Discussion Paper No. 07-063

\title{
Do Equity Preferences Matter in Climate Negotiations? An Experimental Investigation
}

Astrid Dannenberg, Bodo Sturm, and Carsten Vogt

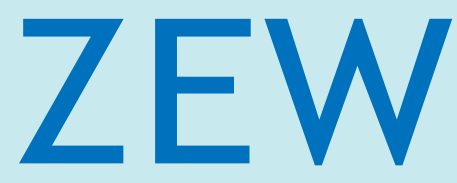

Zentrum für Europäische Wirtschaftsforschung $\mathrm{GmbH}$

Centre for European

Economic Research 
Discussion Paper No. 07-063

\section{Do Equity Preferences Matter in Climate Negotiations? An Experimental Investigation}

Astrid Dannenberg, Bodo Sturm, and Carsten Vogt

Download this ZEW Discussion Paper from our ftp server:

ftp://ftp.zew.de/pub/zew-docs/dp/dp07063.pdf

Die Discussion Papers dienen einer möglichst schnellen Verbreitung von neueren Forschungsarbeiten des ZEW. Die Beiträge liegen in alleiniger Verantwortung der Autoren und stellen nicht notwendigerweise die Meinung des ZEW dar.

Discussion Papers are intended to make results of ZEW research promptly available to other economists in order to encourage discussion and suggestions for revisions. The authors are solely responsible for the contents which do not necessarily represent the opinion of the ZEW. 


\section{Non-Technical Summary}

Although for reaching an agreement in climate negotiations the overall abatement target and hence the total implementation costs of a climate treaty have always played an important role, there is also evidence that climate talks are, to a huge amount, centered around the question of how to share a given abatement burden. Already the Climate Change Convention from 1992 states the basic principle of common but differentiated responsibilities, and numerous other negotiation documents are penetrated by the language of equity.

In this paper we analyze the equity preferences of negotiators in climate policy and try to shed some light on the question about how far equity considerations are important for climate negotiations. We operationalize the notion of equity introducing the concept of inequity aversion developed by Fehr and Schmidt (1999). According to their approach, people are endowed with aversion against advantageous and disadvantageous inequity to a different degree. We measure the degree of inequity aversion of people who have been involved in international climate negotiations with the help of two simple non-strategic games. 116 people from all regions of the world participated in the experiment, which was run via the Internet.

We find that policy-makers exhibit a much stronger preference for equity than students in a comparable study. Possible explanations for this include an education effect, different relevancy of the experimental payoff, and different experience with economic experiments. Considering the geographic variety of respondents' countries of origin in our sample, we cannot confirm significant differences in inequity aversion. Our results are therefore in line with previous findings of behavior in this kind of games which also cannot confirm differences between different regions of the world due to cultural differences. These findings fit the idea that inequity aversion is an anthropological fundamental, not much influenced by socio-economic or cultural circumstances. 


\title{
Do Equity Preferences Matter in Climate Negotiations?
}

\section{An Experimental Investigation}

\author{
Astrid Dannenberg ${ }^{\mathrm{a}}$, Bodo Sturm ${ }^{\mathrm{a}}$, and Carsten Vogt ${ }^{\mathrm{b}}$ \\ ${ }^{\mathrm{a} C e n t r e ~ f o r ~ E u r o p e a n ~ E c o n o m i c ~ R e s e a r c h ~(Z E W), ~ M a n n h e i m ~}$ \\ ${ }^{\mathrm{b}}$ Department of Business Administration, Leipzig University of Applied Sciences \\ E-mail: \\ dannenberg@zew.de, sturm@zew.de,vogt@wiwi.htwk-leipzig.de
}

October 2007

\begin{abstract}
This paper investigates in how far equity preferences may matter for climate negotiations. For this purposes we conducted a simple experiment with people who have been involved in international climate policy. The experiment, which was run via the Internet, consisted of two simple non-strategic games suited to measure the parameters of inequity aversion in a Fehr and Schmidt (1999) utility function. We find that our participants show aversion against advantageous as well as disadvantageous inequity to a considerable amount. Moreover, the degree of inequity aversion is higher compared to that of students in the similar study of Dannenberg et al. (2007). Regarding the geographical variety in our sample, we cannot confirm significant differences in the degree of inequity aversion between different regions in the world, which is in line with previous findings from the experimental literature. This finding lends support to the hypothesis that equity preferences are "hard-wired" and not much influenced by socio-economic or cultural circumstances.
\end{abstract}

JEL classification: C91, C92, H41

Keywords: individual preferences, inequity aversion, climate policy, experimental economics, public goods

Acknowledgements: Financial support from the German Science Foundation is gratefully acknowledged. The authors thank all participants of the Internet experiment and, in particular, Lukas Streisselberger and Torsten Doher for assistance in the technical organization of this study. 


\section{Introduction}

Although for reaching an agreement in climate negotiations the overall abatement target and hence the total implementation costs of a climate treaty have always played an important role, there is also evidence that climate talks are, to a huge amount, centered around the question of how to share a given abatement burden. Already the Climate Change Convention from 1992 states the basic principle of common but differentiated responsibilities, and numerous other negotiation documents are penetrated by the language of equity. Different parties in the climate negotiations refer to different burden sharing principles: Developing countries often point to the fact of much higher per capita carbon dioxide emissions of industrialized countries. They often refer to the egalitarian principle which states that every citizen has the same right to pollute. Consequently, they demand an equalization of per capita emissions at least in the long run. Also, the current proposal of German Chancellor Merkel for a follow-up treaty of the Kyoto Protocol adopts this long-term goal. ${ }^{1}$ Other equity rules refer either to responsibility or ability to cope with the problem of climate change. The polluter-pays rule, for example, claims that abatement costs should be distributed proportionately to a country's share in global emissions. The ability-to-pay rule demands that abatement costs should be shared according to a country's economic capability measured by its GDP. A fourth principle, favored in the past mainly by the United States is the sovereignty rule. It incorporates the idea of an equal percentage emission reduction for all countries, implying also substantial abatement efforts for important, growing developing countries like China or India. All these principles stem from different views on equity and fairness.

The impression that equity considerations play a major role in climate negotiations is supported by a recent survey (Lange et al. 2007b) asking participants of the climate negotiation process about their views on equity. Nearly 80 percent of all respondents state that equity is of very high or high importance in the climate talks. Moreover, this survey identifies important fairness principles that motivate negotiation positions of major negotiation blocks.

\footnotetext{
${ }^{1}$ In a speech given in September 2007 in Tokio, Chancellor Merkel suggested to base a future climate treaty on per-capita carbon dioxide emissions. Moreover, she proposed that industrialized countries should reduce their per-capita emissions while at the same time allowing developing countries like China or India to increase theirs until per-capita emissions are equalized. This resembles the well-known contraction and convergence approach (Meyer 2000).
} 
The EU, for example, is predominantly seen to be driven by the polluter-pays principle while many respondents associate the United States with the sovereignty rule. ${ }^{2}$

Essentially, this evidence can be interpreted in two different ways. First, it could mean that equity principles enter climate negotiations because they reflect deep and serious convictions of the parties involved. Second, one might conjecture that equity arguments are used strategically in order to hide goals which can mainly be traced back to pure material self interest. Lange et al. (2007a), for example, argue that negotiation parties may invoke fairness principles to influence the bargaining outcome in their interest.

Contrary to the latter argument which is rather speculative, there is much evidence that human behavior is indeed driven by equity considerations to a certain extent. Within experimental economics, huge evidence has been collected contradicting the economic model of man based on the two pillars of rationality and pure selfishness. People cooperate in social dilemmas such as public good games (Ledyard 1995), they reject high amounts of money in the ultimatum game (Güth et al. 1982, Camerer 2003) and last but not least they make positive contributions in the dictator game (Kahneman et al. 1986, Forsythe et al. 1994). The contradiction between the standard economic model of selfish behavior and empirical observations has been a challenge for both theorists and experimentalists. In the last ten years a number of theories that try to close this gap in explanatory power have been developed. Most of these theories are based on the assumption that people have some kind of otherregarding, or social, preferences. These approaches seek to overcome the discrepancies between standard game-theoretical prediction and experimental observation by altering the underlying utility function of the subjects, but stick to the assumption that subjects behave rationally. The models by Bolton and Ockenfels (2000) and Fehr and Schmidt (1999) are prominent examples for this approach. They assume that people are willing to sacrifice money in order to avoid unequal payoff distributions. As a matter of fact, both models are able to explain an impressing amount of experimentally observed behavior.

Moreover, these theoretical approaches bear the potential to greatly facilitate the explanation of voluntary cooperation in dilemma situations. Within the framework of a two-stage coalition

\footnotetext{
${ }^{2}$ Not only the political but also the academic debate cares about equity issues. Several papers explore the equitable burden sharing of a given reduction target, e.g. Barrett (1992), Bosello and Roson (2000), Buonanno et al. (2000), LeCocq et al. (2000), Ridgley (1996), Rose (1992), Rose and Stevens (1993) and Rose et al. (1998). Tol (1999) combines cost-effectiveness and intertemporal equity in his analysis. A second branch of the literature searches for those reduction measures that maximize human welfare, e.g. Maddison (1995), Manne et al. (1995), Nordhaus (1991, 1992), Nordhaus and Yang (1996), Peck and Teisberg (1991, 1995) and Tol (1997, 1999). As Kemfert and Tol (2002, p. 24) note, however, these attempts "are based on a narrow neo-classical interpretation of justice".
} 
formation game, Lange and Vogt (2003) prove that coalitions which involve a rather large fraction of countries can be stabilized as a Nash equilibrium when other-regarding preferences are involved. This result stands in sharp contrast to the according results of coalition games which assume a standard preference structure. There, only small coalitions that achieve very little in terms of abatement and welfare can be stabilized (Barrett 1994, Carraro and Siniscalco 1993). According to Lange and Vogt, the critical condition to ensure a large coalition of cooperative countries is the presence of sufficiently many countries with high enough inequity aversion. Already Fehr and Schmidt (1999) prove that partial cooperation can be a Nash equilibrium in a public good game if at least some subjects dispose of sufficiently strong inequity aversion. Since climate protection can essentially be characterized as a social dilemma, the cooperation enhancing effect of equity preferences might also be of practical relevance for real world climate policy. However, whether the critical conditions for cooperative behavior are fulfilled is a question which can be answered only empirically.

Two recent studies explicitly address the question whether the Fehr and Schmidt model (in the following F\&S) has explanatory power in public good games. Blanco et al. (2006) find that the F\&S model has only predictive power at the aggregate level. Building on this study and its experimental design, Dannenberg et al. (2007) find in contrast that F\&S also has predictive power at the individual level. Particularly, they find that subjects with a stronger aversion against advantageous inequity significantly more often cooperate in a public good game. $^{3}$

This result might be of importance for real world cooperation problems. If the chances to come to an agreement depend on the degree of inequity aversion, this should be taken into account. Particularly, it might be more promising to enter into negotiations with countries that are similar with respect to their degree of equity orientation. ${ }^{4}$ Within this context, the question arises whether the findings from the laboratory apply to the real world. A priori it is not clear whether real world negotiators show a degree of inequity aversion like the one discovered in experiments involving students. For example, one could easily imagine that, due to selection or also self-selection mechanisms, real world agents are tougher and less fairness motivated than students. Additionally, the issue of how individual equity preferences relate to the corresponding collective preferences of governments turns up.

\footnotetext{
${ }^{3}$ In Dannenberg et al. (2007), subjects are informed before the public good game about the co-player's type, i.e. his or her inequity aversion. This may have caused the difference in the results compared to Blanco et al. (2006). See Dannenberg et al. (2007) for details.

${ }^{4}$ This argument will be backed up theoretically in section 2 .
} 
The innovative contribution of the present paper consists in suggesting a simple way to include equity preferences into the global climate policy context. Furthermore, we make a first attempt at elicitation and quantification of such equity concerns. Therefore, we carried out simple experiments with people who have been involved in international climate policy. 116 people from all regions of the world participated in an Internet experiment that consisted basically of two simple non-strategic games (named games A and B) introduced by Blanco et al. (2006) suited to measure the parameters of inequity aversion in an F\&S utility function. Game A is designed to measure the subjects' aversion against disadvantageous inequity. The game resembles the responder's basic decision situation in the ultimatum game but abstracts from strategic interaction, such that we can rule out strategic considerations such as intentions or reciprocity. Game B resembles the decision problem in the dictator game and is suited to measure the subjects’ aversion against advantageous inequity.

We find that our participants show aversion against both types of inequity to a considerable amount. Moreover, the degree of inequity aversion is significantly higher compared to that of students in Dannenberg et al. (2007). Regarding the geographical variety in our data, we find that the degrees of inequity aversion between different regions of the world are rather similar. When comparing G8 versus Non-G8 countries and EU versus Non-EU countries we do not find any significant difference in the measured aversion parameters. Only for G77 compared to Non-G77 countries, we find a difference in both types of inequity aversion showing the G77-respondents more inequity avers, but this effect is only weakly significant.

This paper proceeds as follows: In section 2, the theoretical background underlying our study, i.e. the model of Fehr and Schmidt (1999) and its relevance for prognosis regarding individual behavior in a voluntary contribution game is briefly explained. Section 3 describes the experimental design and how the F\&S parameters reflecting inequity aversion are measured, followed by a short description of our subject pool in section 4 . In section 5 , the results are presented. Section 6 gives a discussion of our findings. The last section, as always, concludes.

\section{Theoretical background: The model of Fehr and Schmidt (1999)}

\subsection{Preferences}

According to Fehr and Schmidt (1999) individuals are not exclusively motivated by the absolute payoff they can earn but also value allocations due to their distributional 
consequences. Particularly, assuming that individuals suffer from inequity, F\&S introduce the following utility function for subject $i$ :

$$
U_{i}\left(\pi_{i}, \pi_{j}\right)=\pi_{i}-\alpha_{i} \frac{1}{n-1} \sum_{j \neq i}^{n} \max \left\{\pi_{j}-\pi_{i}, 0\right\}-\beta_{i} \frac{1}{n-1} \sum_{j \neq i}^{n} \max \left\{\pi_{i}-\pi_{j}, 0\right\}
$$

where $\pi_{i}$ and $\pi_{j}$ denote the absolute payoffs to subjects $i$ and $j$, respectively, $n$ denotes the total number of players involved in some decision problem, $\alpha_{i} \geq 0$ measures the impact of $i$ 's disutility from disadvantageous inequity while $\beta_{i} \geq 0$ measures the corresponding impact of advantageous inequity. In the two player case which is particularly relevant for our experimental setting, (1) reduces to

$$
U_{i}\left(\pi_{i}, \pi_{j}\right)=\pi_{i}-\alpha_{i} \max \left\{\pi_{j}-\pi_{i}, 0\right\}-\beta_{i} \max \left\{\pi_{i}-\pi_{j}, 0\right\} .
$$

F\&S assume $\beta_{i}<1$, i.e. players are not willing to "burn" their money to eliminate advantageous inequality. In addition, they assume that players put a greater weight on disadvantageous inequality, i.e. $\alpha_{i} \geq \beta_{i}$. In our experiment, we will obtain the weights $\alpha_{i}$ and $\beta_{i}$ from modified ultimatum and dictator games (see section 3).

\subsection{The voluntary contribution game}

The voluntary contribution game ${ }^{5}$ resembles the basic strategic incentives of a situation where subjects have the possibility to contribute to the production of a global environmental good, such as "climate protection". Assuming standard preferences in a voluntary contribution game, not to contribute to the production of the public good is the Nash equilibrium in dominant strategies although from a social point of view mutual cooperation would be preferable. In other words, if $g_{i}$ denotes a player's individual contribution to the public good and $a$, with $1 / n<a<1$, denote the marginal per capita return (MPCR) of $g_{i}$ then $g_{i}=0$ is the best choice for each player $i$ independently from the other players’ contributions.

\footnotetext{
${ }^{5}$ For a detailed description of this game as a special form of a public good game, see e.g. Dannenberg et al. (2007). Sturm and Weimann (2006) discuss the relevance of this game for experiments in environmental economics.
} 
F\&S have shown that this result is fundamentally altered if players are endowed with inequity aversion according to (1). Let $n \geq 2$ denote the number of players. F\&S prove the following results:

1. If $a+\beta_{i}<1$, then it is a dominant strategy for player $i$ to choose $g_{i}=0$.

2. Let $k, 0 \leq k \leq n$, denote the number of players with $a+\beta_{i}<1$. Then, if $k /(n-1) \geq a / 2$, there exists a unique equilibrium with $g_{i}=0 \forall i \in\{1, \ldots, n\}$.

3. If for all players $j \in\{1, \ldots, n\}$ with $a+\beta_{j}>1$ the condition

$$
k /(n-1)<\left(a+\beta_{j}-1\right) /\left(\alpha_{j}+\beta_{j}\right)
$$

holds, then equilibria with positive contributions to the public good exist. All $k$ players with $a+\beta_{i}<1$ choose $g_{i}=0$ while all other players contribute $g_{j}=g \in[0, y]$.

The intuition behind these results is not too difficult. Firstly, if a player with $a+\beta_{i}<1$ invests one monetary unit in the public good, his monetary return is $a$ while he gains a maximum non-monetary utility of $\beta_{i}$. Now, if the sum of both returns is less than one, it is obviously the best strategy not to invest into the public good, irrespectively of what other players do. Secondly, if there are sufficiently many players with $a+\beta_{j}<1$, then player $j$ will not be willing to contribute even if he shows stronger inequity aversion, i.e. for him $a+\beta_{j}>1$ holds. The reason for that is that relatively few "fair" players are unable to sufficiently reduce disadvantageous inequity. Thirdly, if there are sufficiently many players with $a+\beta_{j}>1$, they can sustain cooperation amongst themselves, "even if the other players do not contribute. However, this requires that the contributors are not too upset about the disadvantageous inequality toward the free riders.” (Fehr and Schmidt 1999, p. 840).

In the following, we use (3) to discuss the meaning of $\alpha_{j}$ and $\beta_{j}$ for the prospects of cooperation explicitly. Let us define $k_{c r i t}:=(n-1)\left(a+\beta_{j}-1\right) /\left(\alpha_{j}+\beta_{j}\right)$, the critical number of non-cooperative countries. First, it is to observe that $\partial k_{c r i t} / \partial \beta_{j}=(n-1)\left(\alpha_{j}+1-a\right) /\left(\alpha_{j}+\beta_{j}\right)^{2}$ which is positive since the MPCR is always less than 1. Hence, an increasing aversion towards advantageous inequity makes cooperation in the voluntary contribution game more likely since (3) is more easily met. Second, considering $\alpha_{j}$ we find 
$\partial k_{c r i t} / \partial \alpha_{j}=(n-1)\left(1-a-\beta_{j}\right) /\left(\alpha_{j}+\beta_{j}\right)^{2}$. For subjects with $a+\beta_{j}>1$ this derivative obviously becomes negative implying that an increasing degree of aversion against disadvantageous inequity makes it more difficult to sustain cooperation amongst "fair" subjects. ${ }^{6}$

To summarize, while a higher degree of advantageous inequity always improves the prospects for a cooperative solution this is not the case for disadvantageous inequity. However, for a given value of $\alpha_{j}$, high values of $\beta_{j}$ are only necessary but not sufficient to ensure stable cooperative outcomes. To attain such a socially preferable outcome, i.e. to exceed the critical value $k_{\text {crit }}$ of non-cooperative countries, the benefit-to-cost ratio of the contribution to the public good has to be sufficiently high.

\section{Experimental design}

We used two different games (games A and B) in our experimental design. The purpose of games A and B was to measure each subject's preferences according to the F\&S model. Game A is designed to measure the subjects' aversion against disadvantageous inequity. The game resembles the responder's basic decision situation in the ultimatum game but abstracts from strategic interaction, such that we can rule out individual behavior caused by strategic considerations such as intentions or reciprocity. ${ }^{7}$ In this game, each subject has to decide in 22 cases (numbered from \#1 to \#22) in the role of Person 1 between two pairs of payoffs (pair I and pair II) each with an amount of money for himself or herself and another subject in the role of Person 2. Payoffs (see the left part of Table 1) are chosen in a way that - except for \#1 - subjects always have to choose between "pair I”, a disadvantageously unequal division of $\$ 200.00$, and “pair II”, an equal distribution with $\$ 40.00$ for both players. All cases were arranged in a descending order by the amount of money subjects could earn with pair I. In this game, a purely selfish subject should choose pair I from \#1 to \#20 and pair II for \#21 and \#22. ${ }^{8}$ A subject strongly disliking disadvantageous inequity, in contrast, would choose pair I in \#1 and pair II from \#2 to \#22. Subjects with other-regarding preferences according to F\&S

\footnotetext{
${ }^{6}$ The parameter $\alpha_{i}$ has additional importance for a public good game with a possibility to punish other subjects at own costs. In such a game, subjects with a sufficiently high $\alpha_{i}$ may enforce cooperation of selfishly motivated subjects. The reason for this is that those "enforcers" are able to exercise a credible threat to punish free riders in order to reduce disadvantageous inequity. See Fehr and Schmidt (1999) as well as Dannenberg et al. (2007).

${ }^{7}$ The difference to the payoffs of the original ultimatum game is the fact that the conflict point payoffs (in \$) are changed to $(40,40)$ instead of the original $(0,0)$.

${ }^{8}$ In the following, we assume rational behavior of all subjects.
} 
between these two extremes would be expected to switch from choosing pair I to pair II after \#2 but prior to \#21.

We describe individual behavior in game $\mathrm{A}$ as consistent if (1.) a subject has a unique switching point from pair I to pair II and (2.) this switching point is between \#2 and \#21. Regarding the first condition, a subject with aversion against disadvantageous inequity consistent with the F\&S model, who switches for a specific case from pair I to pair II should choose for all subsequent cases pair II. As the payoffs for player 1 in pair I are arranged in descending order, a switch back to pair I in any of the subsequent decisions is not consistent. This would lead to a lower own payment and to higher disadvantageous inequity than in the case that was rejected before. In relation to the second condition, it is useful to consider the decision cases outside of the "consistent area” between \#2 and \#21. A subject who chooses pair II in \#1 already is not regarded as consistent because he or she could attain an equal allocation with higher own payoff by choosing pair I. A subject who chooses pair II in \#22 likes disadvantageous inequity, i.e. $\alpha_{i}<0$, and is therefore not consistent with the F\&S model. With the subject's switching point we can determine the upper and lower bounds of the individual $\alpha_{i}$. We approximate the individual value for $\alpha_{i}$ by choosing the mean of the corresponding interval (see Table 1$).^{9}$

Game B - which resembles the decision problem in the dictator game - is designed to measure the subjects' aversion against advantageous inequity. ${ }^{10}$ Again, each subject had to decide between two pairs of payoffs (pair I and pair II) each with an amount of money for himself or herself in the role of Person 1 and another subject in the role of Person 2 in 22 cases (from \#1 to \#22; see the right part of Table 1). Payoffs are chosen in a way that subjects had to choose between "pair I", an extremely unequal but advantageous distribution of $\$ 200.00$, and “pair II”, an equal distribution of different amounts from $\$ 0.00$ to $\$ 210.00$ for each player. All cases were arranged in an ascending order by the amount of money subjects could earn in pair II. In this game, a purely selfish subject would choose pair I from \#1 through \#20 and pair II for \#22. In the case of \#21, this subject would be indifferent between pair I and pair II. A subject strongly disliking advantageous inequity would always choose

\footnotetext{
${ }^{9}$ There are two exceptions to this rule. Firstly, we cannot determine an upper bound for $\alpha_{i}$ of a subject who switches from pair I to pair II in \#2. Therefore, we assign to those subjects the value of the lower bound, $\alpha_{i}=2.18$. Secondly, we assign the value $\alpha_{i}=0$ to a subject who switches from pair I to pair II in \#21, although the corresponding interval for this case is $-0.08 \leq \alpha_{i} \leq 0.04$.

${ }^{10}$ Strictly speaking, game B is equivalent to a reduced form of the dictator game only for decision \#11. However, similar to the dictator game, game B creates a trade-off between own monetary payoff which creates advantageous inequity and a lower but equally distributed payoff.
} 
pair II. Subjects with equity preferences according to F\&S between these both extremes would be expected to switch from choosing pair I to pair II after \#1 but before \#21.

We label individual behavior in game B as consistent if (1.) a subject has a unique switching point from pair I to pair II and (2.) this switching point is between \#2 and \#22., i.e. if the individual weight of aversion against advantageous inequity meets $0 \leq \beta_{i}<1$. Relating to the first condition, a subject with aversion against advantageous inequity consistent with the F\&S model switching from pair I to pair II at one point, should also choose pair II in all cases after the switching point. As the payoffs for Person 1 in pair II are arranged in an ascending order, a switch back to pair I in any of the subsequent cases is not consistent. This would lead to the same advantageous inequity that was rejected before but now with higher opportunity costs in terms of equal payoffs for both players. For the second condition, we consider again the decision cases outside of the “consistent area” between \#2 and \#22. A subject choosing pair II already in $\# 1$ has $\beta_{i} \geq 1$, i.e. is willing to "burn" money in order to produce equal payoffs. A subject who does not switch at all displays affection for advantageous inequity, i.e. $\beta_{i}<0$. Both behavioral patterns are not consistent with F\&S. Similar to game A, we can determine the upper and lower bounds for the individual's $\beta_{i}$ by means of a subject's switching point. We approximate the individual value of $\beta_{i}$ by choosing the mean of the corresponding interval (see Table 1$).^{11}$

A basic assumption underlying our design of games $\mathrm{A}$ and $\mathrm{B}$ is that individuals are only driven by preferences of the F\&S-type. This means in particular that individuals do not hold any specific preferences with regard to "efficiency". An example will help to illustrate this point. In our game B, the sum of both payoffs in pair II rises from $\$ 0$ in \#1 to \$420 in \#22. An individual caring for efficiency only will switch from pair I to pair II after \#10 or after \#11. Given an individual cares for equity and efficiency, we underestimate his or her aversion against advantageous inequity for $\beta_{i}>.53$ and overestimate it for $\beta_{i}<.53$.

\footnotetext{
${ }^{11}$ As before, there is an exception to this rule. We assign the value $\beta_{i}=0$ to a subject who switches from pair I to pair II in \#22, although the corresponding interval in this case is $-0.05 \leq \beta_{i} \leq 0$.
} 
Table 1: Payoffs in game $A$ and game $B$

\begin{tabular}{|c|c|c|c|c|c|c|c|c|c|c|c|}
\hline \multirow{4}{*}{\multicolumn{2}{|c|}{$\#$}} & \multicolumn{4}{|c|}{ game $\mathrm{A}$} & \multicolumn{6}{|c|}{ game $\mathrm{B}$} \\
\hline & & & & & II & \multirow[b]{3}{*}{$\alpha_{i}$} & \multirow{2}{*}{\multicolumn{2}{|c|}{$\frac{\text { pair I }}{\text { ayoffs }}$}} & \multicolumn{2}{|c|}{ pair II } & \multirow[b]{3}{*}{$\beta_{i}$} \\
\hline & & \multicolumn{4}{|c|}{ payoffs (in \$) for person } & & & & \multicolumn{2}{|c|}{ payoffs (in \$) for person } & \\
\hline & & 1 & 2 & 1 & 2 & & 1 & 2 & 1 & 2 & \\
\hline \multirow{22}{*}{ 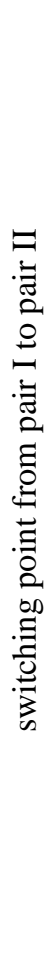 } & 1 & 100.00 & 100.00 & 40.00 & 40.00 & - & 200.00 & 0.00 & 0.00 & 0.00 & 1.00 \\
\hline & 2 & 88.80 & 111.20 & 40.00 & 40.00 & 2.18 & 200.00 & 0.00 & 10.00 & 10.00 & 0.98 \\
\hline & 3 & 88.40 & 111.60 & 40.00 & 40.00 & 2.13 & 200.00 & 0.00 & 20.00 & 20.00 & 0.93 \\
\hline & 4 & 87.80 & 112.20 & 40.00 & 40.00 & 2.02 & 200.00 & 0.00 & 30.00 & 30.00 & 0.88 \\
\hline & 5 & 87.20 & 112.80 & 40.00 & 40.00 & 1.90 & 200.00 & 0.00 & 40.00 & 40.00 & 0.83 \\
\hline & 6 & 86.40 & 113.60 & 40.00 & 40.00 & 1.77 & 200.00 & 0.00 & 50.00 & 50.00 & 0.78 \\
\hline & 7 & 85.80 & 114.20 & 40.00 & 40.00 & 1.66 & 200.00 & 0.00 & 60.00 & 60.00 & 0.73 \\
\hline & 8 & 84.80 & 115.20 & 40.00 & 40.00 & 1.54 & 200.00 & 0.00 & 70.00 & 70.00 & 0.68 \\
\hline & 9 & 83.80 & 116.20 & 40.00 & 40.00 & 1.41 & 200.00 & 0.00 & 80.00 & 80.00 & 0.63 \\
\hline & 10 & 82.80 & 117.20 & 40.00 & 40.00 & 1.30 & 200.00 & 0.00 & 90.00 & 90.00 & 0.58 \\
\hline & 11 & 81.40 & 118.60 & 40.00 & 40.00 & 1.18 & 200.00 & 0.00 & 100.00 & 100.00 & 0.53 \\
\hline & 12 & 78.40 & 121.60 & 40.00 & 40.00 & 1.00 & 200.00 & 0.00 & 110.00 & 110.00 & 0.48 \\
\hline & 13 & 77.20 & 122.80 & 40.00 & 40.00 & 0.85 & 200.00 & 0.00 & 120.00 & 120.00 & 0.43 \\
\hline & 14 & 76.20 & 123.80 & 40.00 & 40.00 & 0.79 & 200.00 & 0.00 & 130.00 & 130.00 & 0.38 \\
\hline & 15 & 73.60 & 126.40 & 40.00 & 40.00 & 0.70 & 200.00 & 0.00 & 140.00 & 140.00 & 0.33 \\
\hline & 16 & 70.60 & 129.40 & 40.00 & 40.00 & 0.58 & 200.00 & 0.00 & 150.00 & 150.00 & 0.28 \\
\hline & 17 & 66.60 & 133.40 & 40.00 & 40.00 & 0.46 & 200.00 & 0.00 & 160.00 & 160.00 & 0.23 \\
\hline & 18 & 57.00 & 143.00 & 40.00 & 40.00 & 0.30 & 200.00 & 0.00 & 170.00 & 170.00 & 0.18 \\
\hline & 19 & 54.40 & 145.60 & 40.00 & 40.00 & 0.18 & 200.00 & 0.00 & 180.00 & 180.00 & 0.13 \\
\hline & 20 & 44.40 & 155.60 & 40.00 & 40.00 & 0.10 & 200.00 & 0.00 & 190.00 & 190.00 & 0.08 \\
\hline & 21 & 28.60 & 171.40 & 40.00 & 40.00 & 0.00 & 200.00 & 0.00 & 200.00 & 200.00 & 0.03 \\
\hline & 22 & 2.00 & 198.00 & 40.00 & 40.00 & -0.14 & 200.00 & 0.00 & 210.00 & 210.00 & 0.00 \\
\hline
\end{tabular}

The experiment was run via the Internet. Participants obtained an individual login which ensured that every individual could take part only once. After subjects logged in, they received an introductory page where the decision problems in games A and B were explained (see Appendix for a full description). Participants were explicitly told that they could earn real money by taking part in this experiment. Next, it was explained in detail how the payoffs from the experiment are determined: From all participants - who have all made their decisions as Person 1 in both games - we randomly selected 10 subjects and matched them into pairs. For each pair we randomly selected one of the games (A or B) and one of the numbers (\#1 to \#22). Finally, we randomly selected for each pair who is Person 1 and who is Person 2. Person 1 then got the money he or she had assigned to himself or herself in the selected number of the selected game. Person 2 got the money Person 1 had assigned to Person 2 in that selected number of the selected game.

Since the payment mechanism involved several random draws, people were advised that the best strategy would be to make every decision in a way as if it were to be realized. We pointed out that each decision - if realized - would not only determine the own payoff but also the payoff of another participant. We also emphasized the fact that although Person 1 
determines the payoff of Person 2, there is no strategic interaction between participants. The instructions were completed by a very short summary of the main five features of the experiment. After that, participants were presented decision problem number A (i.e. game A) followed by a page containing decision problem number B (i.e. game B).

The time necessary to go through all parts of the experiment was about 30 minutes. The expected mean payment per participant (given randomly distributed decisions and our estimate of 100 subjects, which was announced in the instructions) was $\$ 8.63$. Two subjects out of the 116 participants (see section 4) did not go through all parts of the experiments, that is why they were not taken into account for payment. The realized mean payment per participant (10 out of 114 subjects based on real decisions) was $\$ 98.00$, i.e. we finally paid out $\$ 980.00$. All random selections necessary for the payment were drawn up in the presence of a notary. ${ }^{12}$ The money was transferred via Western Union and all participants were informed about their payoff via email. Participants and winners of the experiment remained anonymous, i.e. only the experimenters know their identity and their payoff.

So far the study elicits individual preferences. However, real world climate negotiations are not necessarily governed by the individual preferences of those subjects involved in climate policy. Although preferences of negotiators for equity may play some role in the policy process, they are definitely not the sole determinant of the negotiation process. Governments form some kind of collective preference. This preference formation is a complex matter influenced by factors like voters' preferences of the home country but also preferences of influential interest groups, for example. Despite the fact that it is nearly impossible to give a full explanation of this complicated formation process, we tried to figure out a first idea of what collective (governmental) preferences in climate policy negotiations might look like. Therefore, participants were pleased to imagine that the decisions in games A and B had to be made by a group of representatives of their country on a Conference of the Parties (COP) or a meeting of the Subsidiary Bodies (SB). Respondents then had to indicate how they believed the delegates would decide. Thereby, they were given the following opportunities for game A as well as for game B (see also the Appendix): ${ }^{13}$

\footnotetext{
${ }^{12}$ For the sake of credibility, the contact details of the notary were announced to the subjects (see Appendix).

${ }^{13}$ This approach might appear somewhat naive but we feel confident that these subjects, who have actually been involved in climate negotiations have the best understanding of how to assess the behavior of their government. Answering the question regarding the collective preferences, subjects were not able to change their individual decisions in the beforehand completed games $\mathrm{A}$ and $\mathrm{B}$.
} 
In your opinion, how would the group of representatives of your country decide?

a) the same way as I did.

b) compared to my decision, the decision of the group would lead to a distribution with more money for Person 1.

c) compared to my decision, the decision of the group would lead to a distribution with less money for Person 1.

d) I do not know.

For both games, answer (b), i.e. "more money for Person 1", would indicate, that the subject expects a more selfishly oriented group of delegates. Accordingly, answer (c) indicates a collective inequity aversion which is stronger than in the case of the individual's preference.

The experiment closed by a final questionnaire which asked for several personal characteristics of the participants of our study (e.g. gender, nationality, field of highest degree, type of organization the subjects works for, participation in COP or SB).

\section{Subject pool}

The experiment was run over the course of eight weeks from June 1 until July 30, 2007. A total of 1480 people, who had been involved in climate negotiations before were contacted via mail and asked to participate in the experiment. Two weeks before the deadline, all subjects who had not answered by then received a reminder via email. 116 people took part so that the respond rate was around $8 \%$. The participants came from all over the world, $37.9 \%$ were from Europe, 26.7 \% from Africa, 18.1 \% from Asia, 6.9 \% from South America, 5.2 \% from North America and $5.2 \%$ from Australia and Oceania. The majority of them has its highest degree in natural sciences (43.1\%) followed by engineering (20.7\%), economics and business administration (7.8\%), law (5.2\%), and political sciences (4.3\%). The participants work mostly for national governmental organizations (74.1\%) and universities or research institutions (15.5\%). A few are employed in international governmental organizations (3.4\%), NGO’s (2.6\%), and private companies (0.9\%). Nearly three quarters $(70.7 \%)$ had been to a COP or SB meeting before (see Table 2 for further socio-economic characteristics). 
Table 2: Socio-economic characteristics of participants

\begin{tabular}{|c|c|c|c|c|c|c|c|c|}
\hline \multirow{2}{*}{\begin{tabular}{|l|} 
Participants \\
Frequency \\
\end{tabular}} & \multicolumn{2}{|c|}{ All } & \multicolumn{2}{|c|}{$\begin{array}{c}\text { Consistent } \\
\text { in A }\end{array}$} & \multicolumn{2}{|c|}{$\begin{array}{c}\text { Consistent } \\
\text { in B }\end{array}$} & \multicolumn{2}{|c|}{$\begin{array}{l}\text { Consistent } \\
\text { in A and B }\end{array}$} \\
\hline & Abs. & in \% & Abs. & in \% & Abs. & in \% & Abs. & in \% \\
\hline \\
\hline Female & 24 & 20.7 & 14 & 22.6 & 17 & 22.4 & 11 & 22.0 \\
\hline Male & 87 & 75.0 & 45 & 72.6 & 56 & 73.7 & 37 & 74.0 \\
\hline No answer & 5 & 4.3 & 3 & 4.8 & 3 & 3.9 & 2 & 4.0 \\
\hline \multicolumn{9}{|l|}{ Age } \\
\hline $20-29$ & 13 & 11.2 & 5 & 8.1 & 5 & 6.6 & 3 & 6.0 \\
\hline $30-39$ & 37 & 31.9 & 22 & 35.5 & 27 & 35.5 & 17 & 34.0 \\
\hline $40-49$ & 33 & 28.4 & 17 & 27.4 & 22 & 28.9 & 15 & 30.0 \\
\hline $50-59$ & 27 & 23.3 & 15 & 24.2 & 18 & 23.7 & 12 & 24.0 \\
\hline $60-69$ & 2 & 1.7 & 0 & 0.0 & 1 & 1.3 & 0 & 0.0 \\
\hline No answer & 4 & 3.4 & 3 & 4.8 & 3 & 3.9 & 3 & 6.0 \\
\hline \multicolumn{9}{|l|}{ Continent } \\
\hline AFR & 31 & 26.7 & 9 & 14.5 & 11 & 14.5 & 5 & 10.0 \\
\hline $\mathrm{AOZ}$ & 6 & 5.2 & 2 & 3.2 & 2 & 2.6 & 1 & 2.0 \\
\hline ASI & 21 & 18.1 & 12 & 19.4 & 14 & 18.4 & 9 & 18.0 \\
\hline EUR & 44 & 37.9 & 31 & 50.0 & 37 & 48.7 & 27 & 54.0 \\
\hline NAM & 6 & 5.2 & 3 & 4.8 & 5 & 6.6 & 3 & 6.0 \\
\hline SAM & 8 & 6.9 & 5 & 8.1 & 7 & 9.2 & 5 & 10.0 \\
\hline \multicolumn{9}{|l|}{ EU/Non-EU } \\
\hline EU & 30 & 25.9 & 24 & 38.7 & 26 & 34.2 & 21 & 42.0 \\
\hline Non-EU & 86 & 74.1 & 38 & 61.3 & 50 & 65.8 & 29 & 58.0 \\
\hline \multicolumn{9}{|l|}{ G8/Non-G8 } \\
\hline G8 & 21 & 18.1 & 16 & 25.8 & 19 & 25.0 & 15 & 30.0 \\
\hline Non-G8 & 95 & 81.9 & 46 & 74.2 & 57 & 75.0 & 35 & 70.0 \\
\hline \multicolumn{9}{|l|}{ G77/Non-G77 } \\
\hline G77 & 64 & 55.2 & 27 & 43.5 & 31 & 40.8 & 19 & 38.0 \\
\hline Non-G77 & 52 & 44.8 & 36 & 56.5 & 45 & 59.2 & 31 & 62.0 \\
\hline \multicolumn{9}{|l|}{ Field } \\
\hline Natural sciences & 50 & 43.1 & 25 & 40.3 & 33 & 43.4 & 19 & 38.0 \\
\hline Political sciences & 5 & 4.3 & 3 & 4.8 & 5 & 6.6 & 3 & 6.0 \\
\hline Economics/Business administration & 9 & 7.8 & 6 & 9.7 & 8 & 10.5 & 6 & 12.0 \\
\hline Law & 6 & 5.2 & 3 & 4.8 & 4 & 5.3 & 2 & 4.0 \\
\hline Engineering & 24 & 20.7 & 12 & 19.4 & 11 & 14.5 & 8 & 16.0 \\
\hline Other & 22 & 18.9 & 13 & 20.9 & 15 & 19.7 & 12 & 24.0 \\
\hline \multicolumn{9}{|l|}{ Organisation } \\
\hline International govern & 4 & 3.4 & 3 & 4.8 & 3 & 3.9 & 3 & 6.0 \\
\hline National governmental institution & 86 & 74.1 & 46 & 74.2 & 56 & 73.7 & 36 & 72.0 \\
\hline University or research institution & 18 & 15.5 & 10 & 16.1 & 14 & 18.4 & 9 & 18.0 \\
\hline Private company & 1 & 0.9 & 0 & 0.0 & 0 & 0.0 & 0 & 0.0 \\
\hline NGO & 3 & 2.6 & 1 & 1.6 & 1 & 1.3 & 0 & 0.0 \\
\hline No answer & 4 & 3.4 & 2 & 3.2 & 2 & 2.6 & 2 & 4.0 \\
\hline \multicolumn{9}{|l|}{ COP/SBI or SBSTA participation } \\
\hline Yes & 82 & 70.7 & 44 & 71.0 & 53 & 69.7 & 34 & 68.0 \\
\hline No & 29 & 25.0 & 15 & 24.2 & 20 & 26.3 & 13 & 26.0 \\
\hline No answer & 5 & 4.3 & 3 & 4.8 & 3 & 3.9 & 3 & 6.0 \\
\hline$\Sigma$ & 116 & 100.0 & 62 & 100.0 & 76 & 100.0 & 50 & 100.0 \\
\hline
\end{tabular}

Out of the 116 participants, 62 people (53.4\%) behaved consistently in game A and 76 people (65.5\%) behaved consistently in game B. In total, 50 people (43.1\%) behaved consistently in both games. Our results described in the next section will focus on these three (sub-)groups. The socio-economic characteristics for each group are also shown in Table 2. It is worth noting how greatly the composition sometimes differs between all participants and the three 
groups. For example, while only one quarter (25.9 \%) of all participants is from the EU, they make up almost half (42.0 \%) of the group who behaved consistently in game A and in game B. Conversely, three quarters (74.1\%) of all participants are Non-EU but they make up only $58.0 \%$ of the group who behaved consistently in game A and in game B. The reason for this may be that the participants from the EU have more experience with rather artificial decision situations such as economic experiments.

\section{Results}

Participants in our study (who we will call "policy-makers"14 in the following) care about equity to a considerable amount. The mean value of $\alpha_{i}$ which measures aversion against disadvantageous inequity is 0.368 . The corresponding value for the parameter that mirrors aversion against advantageous inequity is even higher: The mean value of $\beta_{i}$ is 0.590 which is quite high if one takes into account that this parameter is restricted to the interval $[0,1)$.

Figure 1 compares these values to the corresponding findings in the study of Dannenberg et al. (2007) which was essentially identical to the Internet study but used solely students as experimental subjects. Obviously, students care much less about equity: Their mean $\alpha_{i}$ is very low at 0.090 and also $\beta_{i}$ with a mean equal to 0.355 is much below the corresponding value of the respondents in the Internet experiment. The differences in $\alpha_{i}$ and $\beta_{i}$ between both populations are highly significant which is confirmed by a two-sided Mann-Whitney-U-test. ${ }^{15}$

\footnotetext{
${ }^{14}$ This terminology is used just for simplicity. While the majority of our participants actually has been involved in negotiations some respondents answered they had been only observers to the climate talks.

${ }^{15}$ The $p$-values are both 0.000 for $\alpha_{i}$ and $\beta_{i}$. The number of independent observations is $\mathrm{N}=369$ for students and $\mathrm{N}=62(\mathrm{~N}=76)$ for participants in the Internet study in the case of $\alpha_{i}\left(\beta_{i}\right)$. A $p$-value below 0.05 indicates that there is a significant difference in median values between both subject pools.
} 
Figure 1: Cumulated density and mean of alpha and beta (students vs. policy-makers)
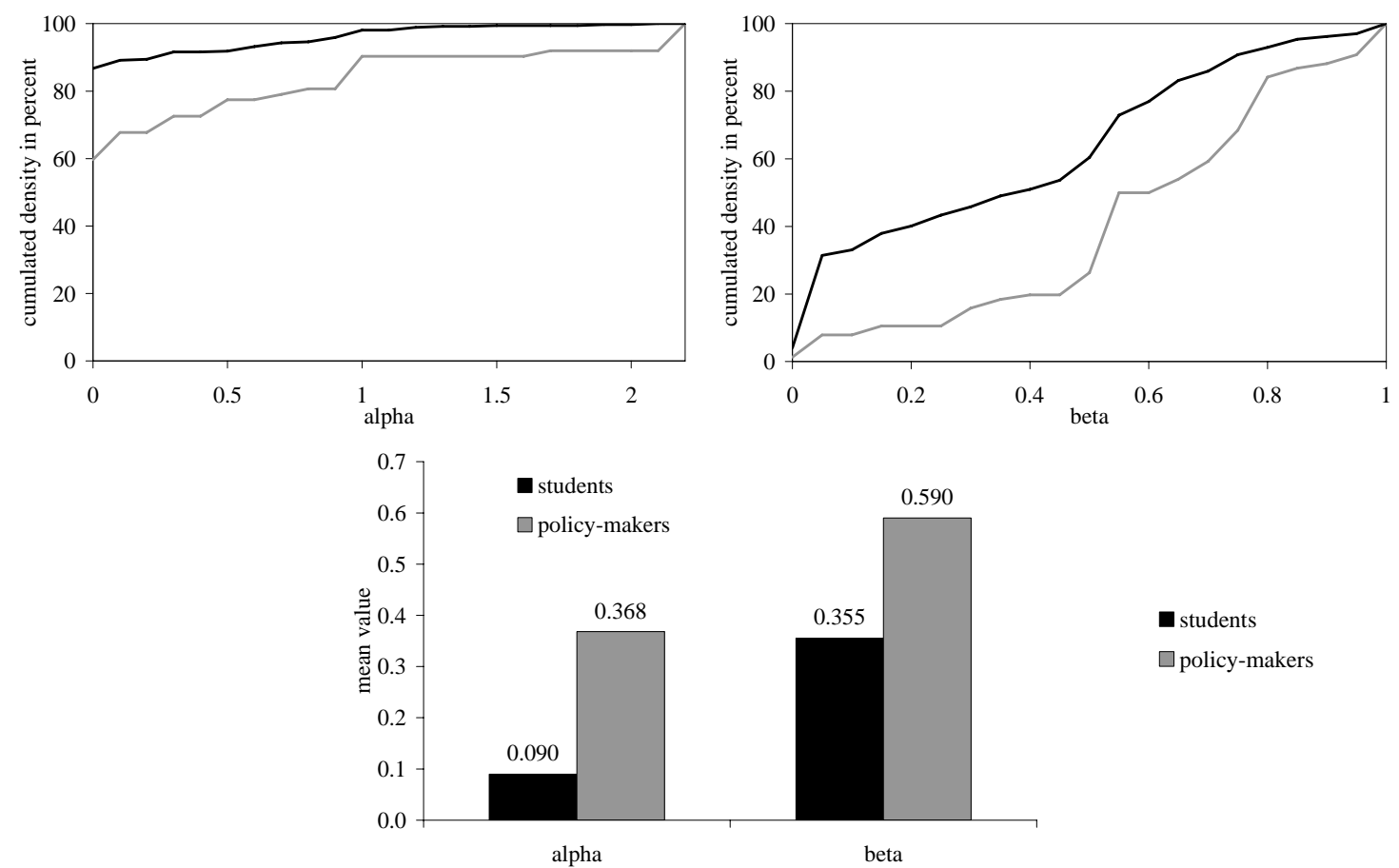

The figure above also shows differences in the distributions of both parameters between the two subject pools, confirming again that participants in the current study are more equity concerned compared to the students. The differences in the distributions of $\alpha_{i}$ and $\beta_{i}$ are highly significant which is tested by a two-sample Kolmogorov-Smirnov-test for equality of distribution functions. ${ }^{16}$

The joint distribution of $\alpha_{i}$ and $\beta_{i}$ of the policy-makers is given in the scatter plot in Figure 2. As one can see, there is a different degree of heterogeneity in the distribution of both parameters. For $\beta_{i}$, there are two peaks each with more than $20 \%$ of the observations at the intervals $(0.5,0.6]$ and $(0.7,0.8]$ indicating that a majority of respondents cares much about advantageous inequity. Contrary to this, a vast majority of participants is not concerned at all with disadvantageous inequity: More than $60 \%$ of all subjects show an $\alpha_{i}$ value of zero. Moreover, it turns out that there is no correlation between both inequity parameters: Spearman's $\rho$ for $\alpha_{i}$ and $\beta_{i}$ is 0.164 with a $p$-value of 0.255 . In addition, we find that only 9 out of 50 subjects obey to the F\&S-condition $\alpha_{i} \geq \beta_{i}$.

\footnotetext{
${ }^{16}$ The $p$-value for $\alpha_{i}$ is 0.001 with $\mathrm{N}=369$ independent observations in the case of students and $\mathrm{N}=62$ observations for policy-makers. The $p$-value for $\beta_{i}$ is 0.000 with $\mathrm{N}=369(\mathrm{~N}=76)$ independent observations for students (policy-makers).
} 
Figure 2: Joint distribution of alpha and beta

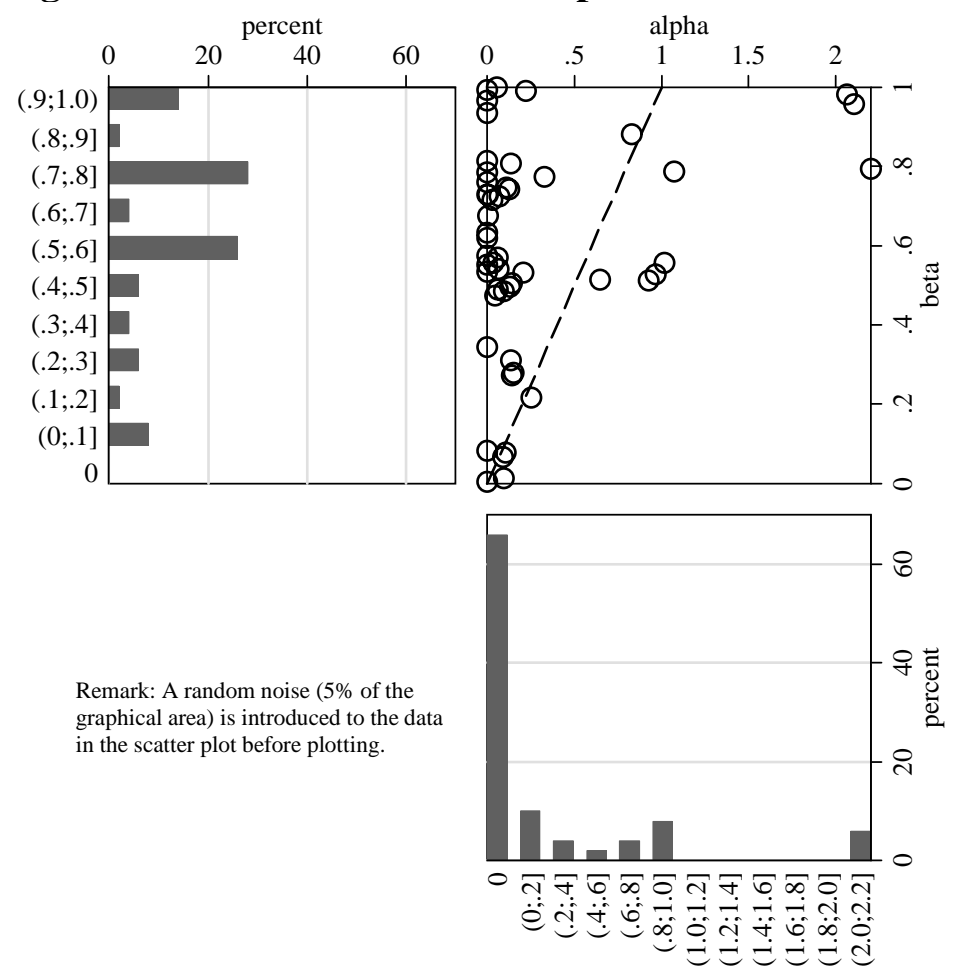

Since there is much geographical variety of respondents in our study, we can check for differences in equity preferences between different regions of the world. The following Table 3 summarizes the results.

Table 3: Regional differences for $F \& S$ parameters

\begin{tabular}{|c|c|c|c|c|c|c|}
\hline & \multicolumn{3}{|c|}{ alpha } & \multicolumn{3}{|c|}{ beta } \\
\hline & mean & MWU test* & KS test* & mean & MWU test* & KS test* \\
\hline $\begin{array}{l}\text { EU vs. Non-EU } \\
\text { EU } \\
\text { Non-EU }\end{array}$ & $\begin{array}{l}0.326 \\
0.395\end{array}$ & 0.282 & 0.637 & $\begin{array}{l}0.542 \\
0.615\end{array}$ & 0.196 & 0.583 \\
\hline $\begin{array}{l}\text { G8 vs. Non-G8 } \\
\quad \text { G8 } \\
\text { Non-G8 }\end{array}$ & $\begin{array}{l}0.301 \\
0.392\end{array}$ & 0.103 & 0.206 & $\begin{array}{l}0.501 \\
0.620\end{array}$ & 0.116 & 0.422 \\
\hline $\begin{array}{l}\text { G77 vs. Non-G77 } \\
\text { G77 } \\
\text { Non-G77 }\end{array}$ & $\begin{array}{l}0.454 \\
0.302\end{array}$ & 0.079 & 0.160 & $\begin{array}{l}0.640 \\
0.556\end{array}$ & 0.073 & 0.079 \\
\hline
\end{tabular}

* $p$-value for the test of significance.

While we cannot confirm significant differences in fairness parameters between EUrespondents versus Non-EU-respondents and G8 versus Non-G8-participants, we find differences when comparing respondents from G77 to subjects that stem from Non-G77countries. G77-subjects have a mean $\alpha_{i}$ of 0.454 which is about $50 \%$ above that of participants from Non-G77-countries (mean $\alpha_{i}$ of 0.302). Also for $\beta_{i}$ there is a corresponding 
difference: G77-respondents show a $\beta_{i}$ of 0.640 on average while the value for Non-G77subjects amounts to 0.556, i.e. the degree of aversion against advantageous inequity of G77participants is about $15 \%$ stronger than of those from the Non-G77. Thus, respondents from G77-countries seem to be more avers against both advantageous inequity as well as disadvantageous inequity. However, both differences are only weakly significant. The twosample Kolmogorov-Smirnov-tests analyzing the differences between the distribution functions of $\alpha_{i}$ and $\beta_{i}$ for G77 versus Non-G77 also show either no significant difference $\left(\alpha_{i}\right)$ or only a weakly significant difference $\left(\beta_{i}\right)$. The differences between G77 and Non-G77 participants with respect to both F\&S parameters are illustrated in Figure 3.

\section{Figure 3: Cumulated density and mean of alpha and beta (G77 vs. Non-G77)}
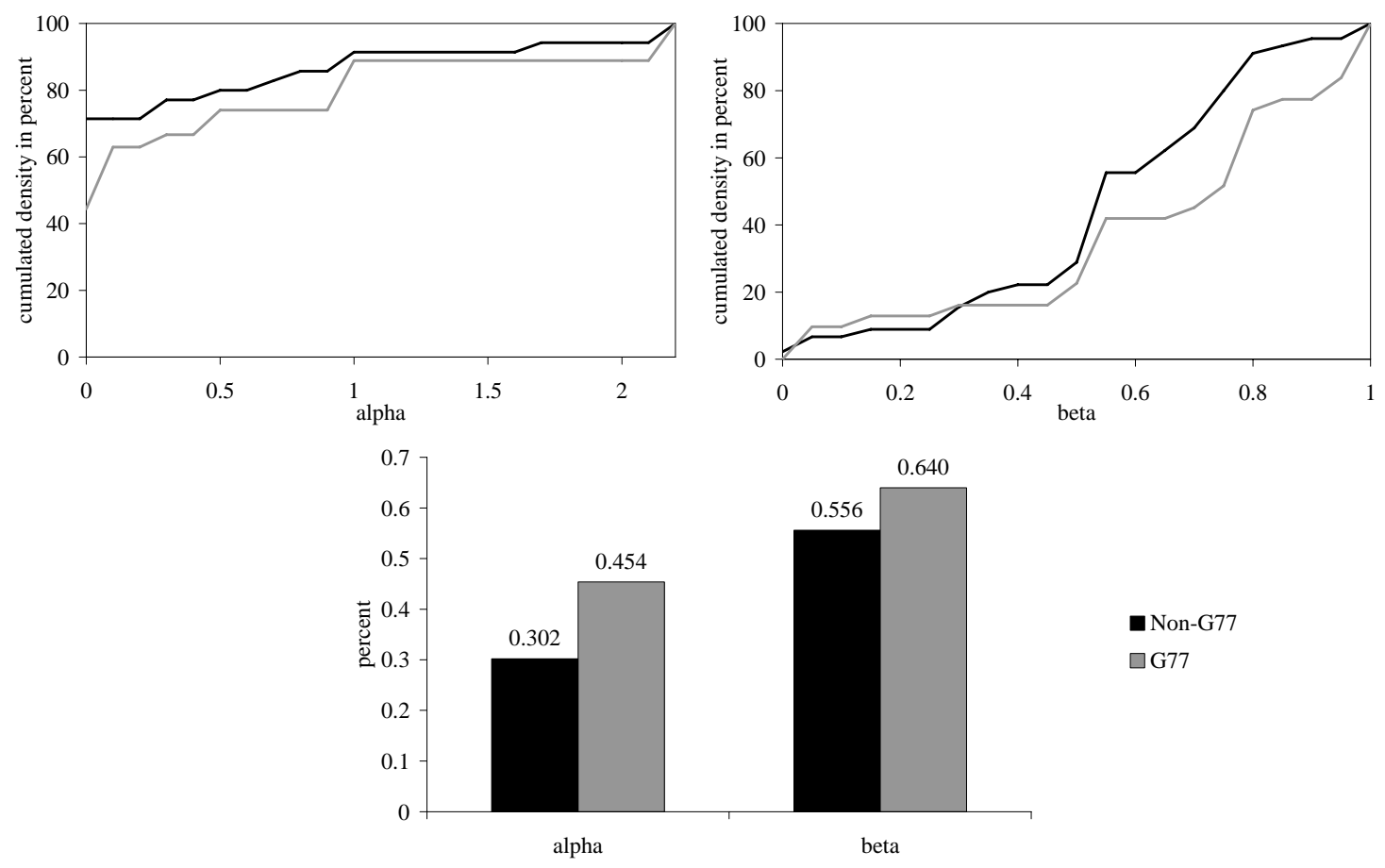

Next, let us turn to our respondents' conjecture about the collective fairness preferences. Interestingly, most participants have stated how their individual fairness preference relates to the collective preference. Only about $16 \%$ of subjects fall into the category "Do not know" as one possible answer to this question. The following Figure 4 contains frequencies of answers separated for subjects whose inequity parameter values lie above and below the mean value. Consider $\alpha_{i}$ first. On the one hand, nearly $64 \%$ of those who are less averse against disadvantageous inequity, i.e. who have an $\alpha_{i}$ below the mean value, would also expect their country delegates to not act very fairness-oriented. $13.6 \%$ expect them to act even more selfish, i.e. to claim a higher amount of money for Person 1. On the other hand, a clear 
majority of those who care more about equity and show $\alpha_{i}$ values above the mean expect their country delegates to behave more selfishly: About $47 \%$ of the respondents expect them to claim more money for Person 1 than for themselves. Only about $29 \%$ think that their representatives would act much the same way they did. The distribution of answers for the two subpopulations "above mean" and "below mean" are significantly differently distributed which is confirmed by a two-sided Chi-square test. ${ }^{17}$ Taken together, we can summarize that only a small minority of respondents expects country delegates to act in a more fairnessoriented way. A vast majority of both subpopulations assumes rather selfish decisions of the country delegates: Most "below mean” participants expect them to behave the same way, i.e. to have equally low $\alpha_{i}$ values, and the majority of the "above mean" participants expect them to have lower $\alpha_{i}$ values.

Figure 4: Collective vs. individual preference for inequity aversion
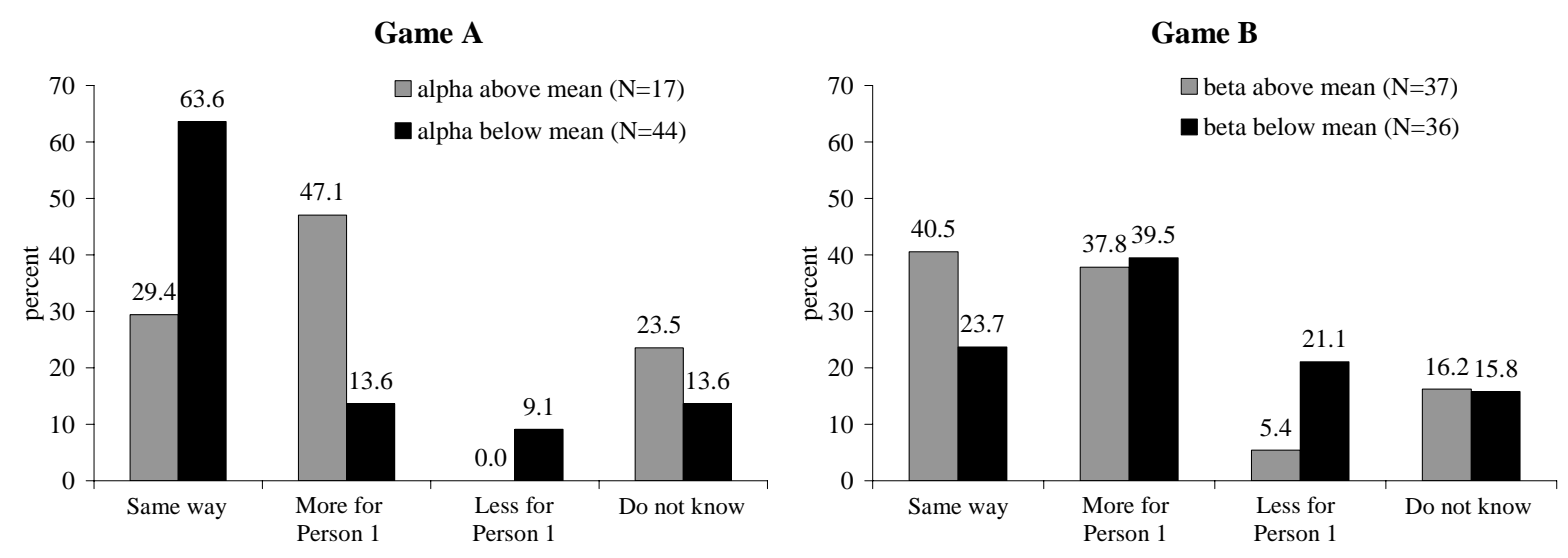

Looking at $\beta_{i}$ we find a slightly different and more ambiguous picture. Out of those who are less averse against advantageous inequity, only about a quarter expect the same degree of inequity aversion regarding the collective preference, while nearly $40 \%$ expect governments to be more, and about $20 \%$ to be less selfish. About $41 \%$ of those showing values above the mean expect their delegates to behave the same way they did, but a percentage nearly as high expects representatives to act more selfishly. The answers for the two subpopulations are distributed differently. ${ }^{18}$ Thus, again a majority of respondents does not expect governments to act in a more fairness-oriented way. However, unlike game A, the expectations of both

\footnotetext{
${ }^{17}$ We conducted a two-sided Chi-square test on the individual level. The number of independent observations is 17 and 44 , respectively. The obtained $p$-value is 0.000 .

${ }^{18}$ The $p$-value is 0.000 (two-sided Chi-square test). The number of independent observations is 37 and 36, respectively.
} 
subgroups are different: The majority of the "above mean" participants think that the representatives are equally fair whereas the majority of the "below mean" participants expect them to be even more selfish than themselves. Furthermore, the answers of the "below mean" subpopulations in game A and game B are significantly differently distributed while answers for the “above mean” subpopulations are not. ${ }^{19}$

The conclusions from Figure 4 regarding the individual and collective preferences for inequity aversion are partly supported by the Probit estimates in Table 4. It becomes obvious that both F\&S parameters elicited for each individual have significant explanatory power for the expected collective preferences, even if we control for other personal characteristics. The results are quite intuitive: A higher $\alpha_{i}$ leads to a lower probability to answer "Same way" but to a higher probability for "More for Person 1". Thus, people with higher aversion against disadvantageous inequity do not expect their government to have the same degree of aversion but rather to be less avers against disadvantageous inequity. Regarding game $\mathrm{B}$, a higher $\beta_{i}$ leads to a higher probability to answer "Same way" but to a lower probability for "Less for player 1". Thus, people with higher aversion against advantageous inequity do not expect their government to be more inequity averse but rather to have the same degree of aversion against advantageous inequity. This result is also in line with Figure 4. However, the model fit for game B is worse than the one for game A. Hence, we should regard the interpretation of the corresponding data in game $\mathrm{B}$ with care.

The interpretation of results for game B is furthermore difficult due to possible confounding effects of preferences for "efficiency". ${ }^{20}$ The fact that about $38 \%$ of “above mean” subjects answer "More for Person 1" may be caused by the expectation that their government either is more selfishly orientated or has a stronger preference for efficiency. The same holds for the $21 \%$ of "below mean" subjects who indicate that their government will give "Less for Person 1 ” as an answer. The reason for this may be either a higher degree of collective equity preference or a stronger preference for a higher total payoff.

\footnotetext{
19 The $p$-value is 0.000 (two-sided Chi-square test) for the "below mean" subpopulations. The $p$-value is 0.381 (two-sided Chi-square test) for the "above mean" subpopulations.

${ }^{20}$ Remember, that the mean value of $\beta_{i}$ is equal to 0.59 which correspondents to the switching point \#10 (see Table 1).
} 
Table 4: Probit estimates

\begin{tabular}{lccccc}
\hline Game A & alpha & age & field engineer & no COP participation & Ps. R2 \\
Same way & $-0.514^{*}$ & $-0.066 * * *$ & $-0.976^{*}$ & 0.502 & 0.213 \\
More for player 1 & $0.810^{* * *}$ & $0.043^{* *}$ & $0.767 *$ & $-1.284 *$ & 0.218 \\
& & & no COP participation & Ps. R2 \\
Game B & beta & & & $0.808 * *$ & 0.101 \\
Same way & $1.210^{*}$ & & & -0.648 & 0.121 \\
Less for player 1 & $-1.669 * *$ & & & & \\
\hline
\end{tabular}

Remarks

(1) $* * * / * * / *$ indicates significance at the $1 / 5 / 10 \%$ level. The number of observations is 61 (73) for game A (B).

(2) The variables "field engineer" and "no COP participation" are dummies for the corresponding attribute of the subject.

(3) For game A, due to lack of data no estimate for "Less for player 1" is possible. For game B, estimates for "More for player 1" are not presented because of no significant results. Furthermore, variables "age" and "field engineer" are not included due to no significant impact.

(4) The probit estimates can be divided by 2.5 to make them comparable to the OLS slope estimates and to interpret them as marginal effects on the probability to choose the corresponding category. See Wooldridge (2000), p. 537.

\section{Discussion}

From a policy-oriented point of view, the most interesting and also important question might be what the implications of our findings for real world climate negotiations are. The answer is not quite easy and one has to be very cautious: Real world climate policy is a complex matter dealing with many more influences than equity attitudes only. Moreover, as already mentioned we have to be aware that equity preferences as measured in our study are not identical to collective preferences of countries. Despite this fact, the individual preferences of policy-makers in our study may serve as a starting point for a discussion of the role of equity for cooperation of countries in climate policy. As a vast majority of participants in our study expects governments to not act in a more equity-oriented way, the individual preferences can be seen as an upper bound for inequity aversion reflected in collective preferences.

The voluntary contribution game introduced in section 2 lacks many features of the real world climate problem, e.g. an explicit modeling of costs and benefits of climate policy and their regional distribution. However, it captures the essential incentive problem that the international community faces, namely the voluntary provision of the global public good “climate protection”. Thus, let us assume that this game can be seen as a rough approximation of the incentive problem underlying real world climate negotiations. What do our findings then imply within this modeling context?

The critical condition for achieving cooperation is given as $k /(n-1)<\left(a+\beta_{j}-1\right) /\left(\alpha_{j}+\beta_{j}\right)$. This condition (see section 2) implies a lower bound for the critical value of $k, k_{c r i t}$, the number of countries that will defect in any case. We obtain for the lower bound 
$k_{c r i t}>0 \Leftrightarrow a+\beta_{j}-1>0 \Leftrightarrow a>1-\beta_{j}$. Obviously, an increasing degree of aversion against advantageous inequity makes it easier to meet this requirement. To state it the other way round: Low values of $\beta_{i}$ imply that cooperation can only be obtained if $a$, i.e. the MPCR of climate mitigation policies, is sufficiently high. In our study, we find a mean value for $\beta_{i}$ of 0.590. Let us for convenience neglect the rather small regional differences and consider this mean value for $\beta_{i}$ only. Our empirical finding then implies that cooperation could be obtained only if $a>0.41$.

Of course, currently nobody can tell whether the return of climate mitigation policies is above or below 0.4. However, what matters in real world policies is the perceived return. Some countries have been very skeptical about the merits of mitigation policies in the past. The United States for example heavily pointed to the implied costs while at the same time rising doubts whether there are any benefits of climate policy at all. This observation leads to the conclusion that the perceived MPCR for the US in the past might have been very low, offering some explanation why the US have been so hesitant to adopt an active climate mitigation policy. ${ }^{21}$ On the other side, the Europeans predominantly have been very optimistic about net benefits of climate policy, giving some explanation for their self-declared leadership in climate policy. Thus, although Europeans and Americans may bother about equity roughly to the same amount, this may not be sufficient to reach agreement in climate mitigation policy. What is needed in addition is a commonly shared view about sufficiently high net benefits of such policies. In other words, strong equity preferences are only necessary but not sufficient for a successful climate agreement. Besides equity preferences, sufficiently high net benefits of the contribution to climate protection are required in order to ensure a stable cooperative outcome.

Moreover, condition (3) may offer part of an explanation as to why the US dropped out of the Kyoto Protocol. If we interpret $a$ as the perceived MPCR of mitigation policies, one might speculate that for the Clinton-Gore administration, the return of active climate policy was high enough in order to assure that $a+\beta_{j}-1>0$, thus allowing for the possibility to take part

\footnotetext{
${ }^{21}$ So even if Americans are concerned about equity issues, too, this does not automatically lead to the decision to contribute to the global public good "climate protection". The simple voluntary contribution game shows that inequity aversion is not the sole determinant for the decision to cooperate, but high enough returns of cooperative behavior have to be guaranteed as well. Note that we have no reason to assume that (North) Americans are less concerned about equity issues than the average. The average value of $\beta_{i}$ for participants from the US and Canada is 0.52. Unfortunately, only five subjects from North America participated in our study, so we cannot claim representativeness.
} 
in a climate treaty. Even if $a+\beta_{j}-1>0$ there still remains the problem of what an acceptable number of countries abstaining from their own substantial obligations would be. This issue has been discussed extensively in the US and the US Senate, for example, unanimously argued that important developing countries should not be allowed to stay outside the Kyoto Protocol. ${ }^{22}$ In any way, for the Bush administration, the perceived MPCR of climate policy has presumably been much lower, such that $a+\beta_{j}-1<0$, making participation in a climate treaty no longer worthwhile.

In the following, we turn to a discussion of some more specific results of our study. Although we find a difference regarding the degree of inequity aversion between participants from G77 and Non-G77 countries, it has to be noted that it is only weakly significant. Moreover, considering alternative groupings of countries like G8 versus Non-G8 or EU versus Non-EU countries we are not able to detect any significant differences. Given the huge differences in socio-economic circumstances between different regions of the world, this is a remarkable result. On the one hand one could expect poorer countries to put a much higher weight on equity compared to the industrialized world. On the other hand it might be possible that people with a low income act in a more selfish way. Actually, we do not find clear evidence for either of them. Employing regressions in order to explain both F\&S parameters by means of several independent variables, we could confirm only very few significant effects. In Table 4, we depict the results for two models with various socio-economic and geographical characteristics (age, gender, field of education, status as negotiator, origin) and either the percapita $\mathrm{CO}_{2}$ emissions or the per-capita GDP of the participant's home country. Interestingly, subjects with a degree in political science $\left(\alpha_{i}\right.$ and $\left.\beta_{i}\right)$ and engineering science $\left(\beta_{i}\right)$ exhibit significantly lower F\&S inequity aversion. ${ }^{23}$ Furthermore, $\alpha_{i}$ is negatively influenced by the per-capita GDP and the per-capita $\mathrm{CO}_{2}$ emissions. However, this effect is only weakly significant and the fit of the corresponding models is rather unsatisfying. Both models do not show any other significant effects.

\footnotetext{
${ }^{22}$ This has been codified in the Byrd-Hagel resolution passed with unanimity before COP3 in 1997. The ByrdHagel resolution makes own substantial reduction measures of important developing countries a prerequisite for the US to participate in the Kyoto Protocol. Although many have conjectured that this resolution was motivated purely strategically, our discussion shows that there might be some underlying economic rationale, since it could be the result of a positive but still too low perceived return of climate policy.

${ }^{23}$ However, we have no proper explanation for this result. Usually one would expect economists to show lower inequity aversion (see e.g. Dannenberg et al. 2007) but this is actually not what we observe.
} 


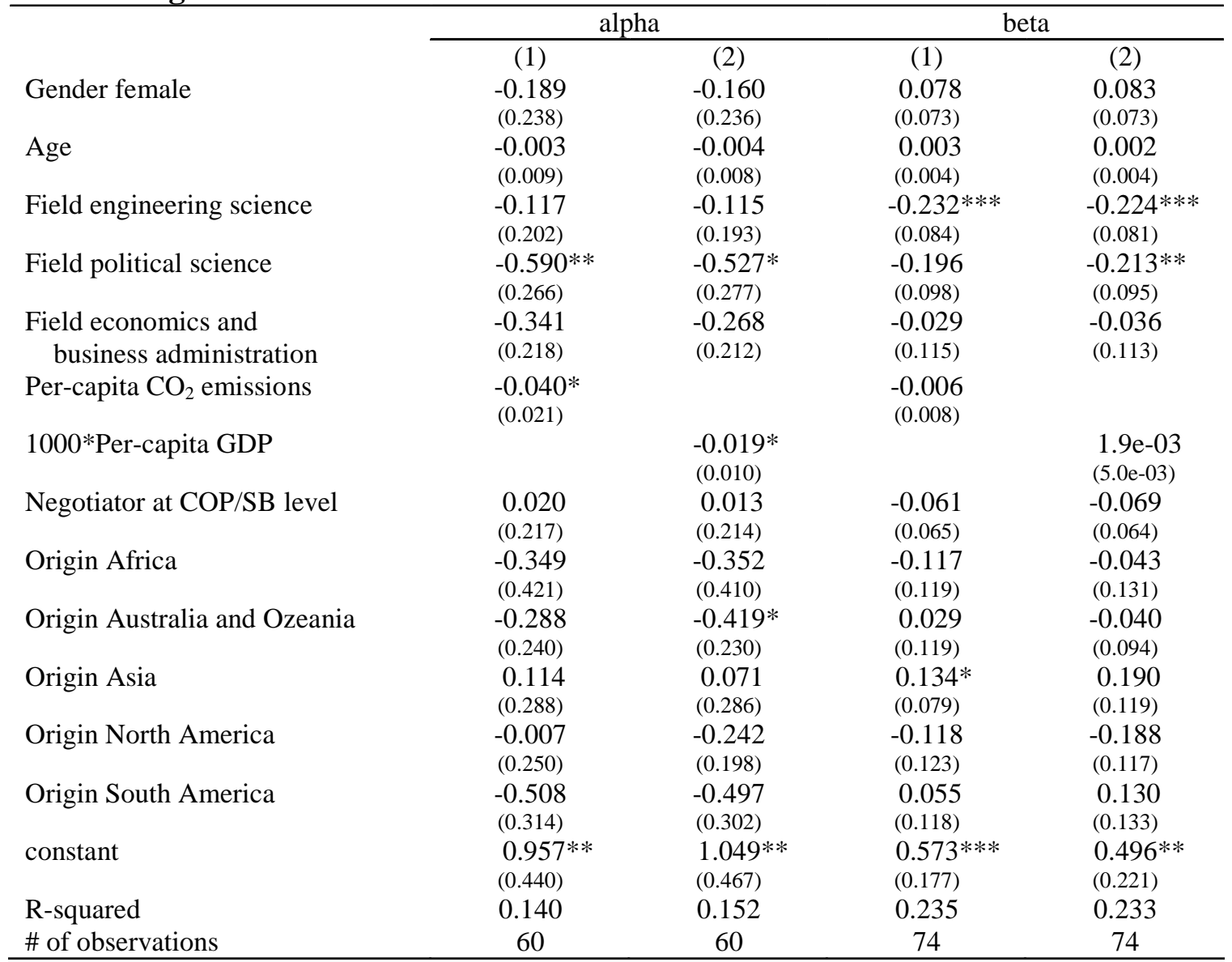

Note: Robust standard deviations in parentheses. $* * * * * * *$ indicates significance at the 1/5/10\% level.

With respect to $\beta_{i}$ one has to bear in mind that our results could be driven by confounding effects of preferences for efficiency. As mentioned earlier, for $\beta_{i}<0.53$ our design overestimates aversion against advantageous inequity while for $\beta_{i}>0.53$ it is underestimated. This is due to the fact of a non-constant size of the pie in the egalitarian decision cases. Now imagine it were possible to separate pure inequity aversion from efficiency. Then our result of rather similar values for $\beta_{i}$ would not necessarily be due to similar equity attitudes. Rather, it could be that subjects with low pure inequity aversion hold strong preferences for efficiency and vice versa. For future research on the reasons for cooperative behavior in social dilemma situations, it would be highly interesting and desirable to decompose these two effects. ${ }^{24}$

\footnotetext{
${ }^{24}$ Previous experimental evidence with respect to this question is mixed. While some papers identify situations where a preference for efficiency seems to have a dominant effect (see e.g. Engelmann and Strobel 2004, Andreoni and Miller 2002) others argue that efficiency concerns are dominated by fairness concerns, i.e. by inequity aversion (see e.g. Güth et al. 2003, Levati et al. 2007). For our purposes, further research on this question should focus on the specific strategic incentives of social dilemma situations.
} 
To sum up, neither the non-parametric tests nor the regression models find significant differences between regions. We have to conclude therefore that inequity aversion on average is rather similar across regions - at least if one compares similar groups, namely people involved in international climate negotiations, from different countries. This finding is in line with the literature. Oosterbeek et al. (2004) carried out a meta-analysis of 37 ultimatum game experiments looking for differences in the subjects' behavior. They find that there are no significant differences in the behavior of responders in the ultimatum game that can be traced back to cultural differences or socio-economic differences. ${ }^{25}$

Our findings support the hypothesis that inequity aversion is a rather "hard-wired" disposition of human behavior that has developed during the human evolution. Thus, one should expect the distribution of such equity parameters to be rather similar when comparing different populations. However, we have to concede that our data basis is rather small. It might be that an investigation based on a broader data set comes to different conclusions. Moreover, it could be that per-capita GDP of the respective country is not a good proxy for the individual income of our respondents, which might be able to explain individual differences better, but is difficult to collect. We have to remember that all of our participants work in the field of climate policy so that they do not constitute representative groups of their home countries. The income of the participants from developing countries is presumably above the average of the country. Therefore, if the individual income was indeed an influencing factor of the degree of inequity aversion, the comparison between representative samples from developing versus industrialized countries would probably show greater differences. The answer to this question, however, remains to future research.

For us, it remains to discuss and explain the highly significant difference in degrees of inequity aversion between students and policy-makers. Partly, this may be due to an education effect. Since the beginning of economic experiments, it has been repeatedly documented that economists are less cooperative in dilemma games and less fair in bargaining games. The two subpopulations in the current study and in Dannenberg et al. (2007) differ in this respect: While only about $8 \%$ of our participants hold a degree in the field of economics and business administration, the corresponding percentage in our comparison study is higher than $60 \%$. Due to several problems such as the absence of overlapping characteristics (e.g. age, degree)

\footnotetext{
25 This implies that the $\alpha_{i}$ values of participants in the experiments analyzed in Oosterbeeck et al. do not significantly differ. Thus, strictly speaking we can only conclude that our result regarding $\alpha_{i}$ is in line with the literature. We are not aware of a similar meta-study analyzing dictator games or modified dictator games which would allow comparisons of $\beta_{i}$.
} 
within both populations, we have not been able to investigate this hypothesis statistically. It could also be that differences in the average income of students and policy-makers matter for the measured difference in experimental behavior. The average earning of students in the experiments of Dannenberg et al. (2007) were about $€ 6$ while participants in this study earned $\$ 8.63$ on average, which is roughly the same amount. However, €6 is presumably a much higher share of a student's total monthly income than of the income of a diplomat or a scientist. Since the relative amount is thus higher for students, this may explain why they decided in a more selfish way. Another possible explanation is the experience with economic experiments. About $69 \%$ of the students had participated in laboratory experiments before. Therefore, they were certainly more conversant with such decision situations which might lead to more selfish decisions. ${ }^{26}$

\section{Conclusion}

In this paper we tried to shed some light on the question about how far equity considerations are important for climate negotiations. We operationalize the notion of equity introducing the concept of inequity aversion developed by Fehr and Schmidt (1999). According to their approach, people are endowed with aversion against advantageous and disadvantageous inequity to a different degree. We measure the degree of inequity aversion of people who have been involved in international climate negotiations with the help of two simple games which resemble the decisions in a dictator and an ultimatum game. Our main finding is that policy-makers care about inequity to a considerable amount. Since the participants of our experiment do not expect their governments to be more inequity avers but rather to be equally avers or to be more selfish, we can take the measured individual inequity aversion as upper bound for the collective preferences.

If one accepts the simple voluntary contribution game as a rough approximation of the essential incentive problem underlying real climate policy, two key variables turn out to be decisive for the success of international climate negotiations: First, parties have to be endowed with sufficiently strong equity preferences. Second, parties must expect sufficiently high net benefits from mitigation policies, i.e. technically speaking they have to expect a high enough marginal per capita return from their contribution to the public good. Our empirical estimates for the degree of inequity aversion raise doubts about whether the latter condition

\footnotetext{
${ }^{26}$ This would be in line with Brosig et al. (2007) who observe a strong erosion of other-regarding preferences over a sequence of several dictator and prisoner's dilemma games.
} 
has been fulfilled in the past for all countries. Thus, differences in the perceived MPCR of climate policy may be part of an explanation why Europeans claimed leadership in climate policy and why the US abstained.

We find that policy-makers exhibit a much stronger preference for equity than students. Possible explanations for this include an education effect, different relevancy of experimental payoffs, and different experience with economic experiments. Considering the geographic variety of respondents' countries of origin in our sample, we cannot confirm significant differences in inequity aversion. Our findings are therefore in line with the literature which also cannot confirm such differences in this kind of games between different regions of the world due to cultural differences. These findings fit the idea that inequity aversion is an anthropological fundamental, not much influenced by socio-economic or cultural circumstances. We have to bear in mind, however, that our participants are not representative samples of their home countries but rather work all in the same field, namely the international climate policy. 


\section{Appendix}

This appendix includes the instructions and the decision problems for the internet experiment:

\section{Login}

\section{Internet Experiment for Decision Makers in International Climate Policy}

This study is organized and executed by a research team of the Centre for European Economic Research (ZEW) Mannheim/Germany.

Please enter your login.

Login:

If you have problems or questions concerning the questionnaire, don't hesitate to send a message to sturm@zew.de

\section{Introduction}

\section{Introduction}

This internet experiment consists of three parts:

1. Instructions

2. Decision Problems

3. Some Questions About Yourself

Please go through all parts. Otherwise, we cant guarantee that your decisions will be regarded as valid. If you break off the experiment, you can continue at any time by signing back in with your login. However, your data will not be considered for analysis and payment until you have finished the experiment completely.

Please click "OK" to continue with part one: Instructions

\section{Instructions 1}

\section{Instructions}

In this experiment you have the chance to earn real money, up to $\$ 210$. You need, however, some time and concentration to go through the instructions. Please read all the instructions carefully. Your decisions in the experiment will be anonymous. Only the experimenter, i.e. the ZEW research team, will get to know your identity, but all data will be treated confidentially.

In the experiment you will have to make decisions in two Decision Problems, $A$ and $B$. The rules of the Decision Problems as well as the payment of money will be explained in the following. If you have any questions, please contact Dr. Bodo Sturm via e-mail (sturm@zew.de).

1.1 Rules for the Decision Problems $A$ and $B$

There are two persons, Person 1 and Person 2, in the Decision Problems $\mathrm{A}$ and $\mathrm{B}$. Certain amounts of money will be split between the two persons. There are two options, Option I and Option II, to split the money.

Person 1 always has to select one of the two options. Person 2 has no choice but has to accept the decision made by Person 1 .

In the experimentyou will always decide in the role of Person 1, i.e. you will decide how to split the money between yourself (Person 1) and Person 2. You have to choose between the two options 22 times in Decision Problem $A$ and 22 times in Decision Problem $B$.

\section{Examples}

Below, you can see an example for the Decision Problem A (Decision Problem $\mathrm{B}$ looks similar). In the example, only the decision of Person 1 in No. 5 is depicted. Later in the experiment there will be No. 1 to No. 22. Person 1 has chosen Option I in No. 5 (as indicated with "X"). The decision depicted in the example would assign $\$ 90.00$ to himself or herself and $\$ 110.00$ to Person 2 . Option II would have assigned $\$ 40.00$ to both persons.

Decision Problem A

Person 1 chooses between Option I and Option II.

- Payoff in US\$ -

\begin{tabular}{|c|c|c|c|c|c|c|}
\hline \multirow[b]{2}{*}{ No. } & \multicolumn{3}{|c|}{ Option I } & \multicolumn{3}{|c|}{ Option II } \\
\hline & Choice & Person 1 & Person 2 & Choice & Person 1 & Person 2 \\
\hline$\ldots$ & & $\ldots$ & $\ldots$ & & $\ldots$ & $\ldots$ \\
\hline 5 & $x$ & 90.00 & 110.00 & & 40.00 & 40.00 \\
\hline$\ldots$ & & $\ldots$ & $\ldots$ & & $\ldots$ & $\ldots$ \\
\hline
\end{tabular}

Please click "OK" to continue with the second part of the instructions: Determination of Payoffs 


\section{Instructions 2}

\section{Instructions}

1.3

\section{Determination of Payment}

As mentioned above, you have the chance to earn real money in this experiment. Whether you will get money and how much depends on two factors: (1.) your decisions in the Decision Problems $\mathrm{A}$ and $\mathrm{B}$ or the decisions of other participants in the Decision Problems $\mathrm{A}$ and $\mathrm{B}$ and (2.) chance.

We expect about 100 participants in total in the experiment. Each of them runs through the same decision problems, i.e. all of the participants decide as Person 1 in Decision Problems A and $B$. After completion we randomly select 10 participants and match them into pairs. For each pair we randomly select one of the Decision Problems (A or $B$ ) and one of the numbers (No. 1 to 22). Finally, we randomly select for each pair who is Person 1 and who is Person 2. Person 1 will get the money he or she has assigned to himself or herself in the selected No. of the selected decision problem. Person 2 will get the money Person 1 has assigned to Person 2 in that No. of the selected decision problem. For the sequence of random draws, see figure below. All random selections will be drawn up before a notary (Mr. Werner Eichorn, Mannheim/Germany, see: Www.notar-eichhorn.de).

This payment rule has the following consequences:Your decisions may not only determine your own earnings but also the earnings of another participant. As a random draw decides who finally is selected Person 1, there is no interaction between participants. If you randomly end up as Person 2 there is no possibility to influence the decisions of Person 1 . Each of the 44 decisions you will have to make in the Decision Problems $\mathrm{A}$ and $\mathrm{B}$ has the same probability to be realized. Thus, the best strategy is making every decision in a way as if it were to be realized.

The money will be disbursed via Western Union (see whw.westernunion.com) without any organizational effort for you. In any case, al participants will be informed about the individual payment from the experiment via e-mail, i.e. you will be informed only about your own payment. Therefore, please do not forget to indicate your e-mail address at the end of the experiment.

\section{Random Draw}

Selection of 10 persons from all participants

2. Random Draw

Matching of selected persons into pairs

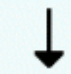

3. Random Draw

Selection of the decision problem ( $A$ or $B)$ for each pair

4. Random Draw

Selection of the number (between No. 1 and 22) for each pair

5. Random Draw

Selection of Person 1 and Person 2 for each pair

Payment

Please click "OK" to continue with a Summary of the instructions.

\section{Instructions 3}

\section{Instructions}

\subsection{Summary}

Before the experiment will start, please remember the most important features:

1. You have the chance to earn real money.

2. Your decisions may determine not only your own earnings but also the earnings of another participant.

3. There is no interaction between participants.

4. All participants decide as Person 1 Whoever will be selected Person 1 or Person 2 in the end is random.

5. The best strategy is making every decision in a way as if it were to be realized.

If you have any questions, please contact Dr. Bodo Sturm (sturm@zew.de).

Please click "OK" to continue with part two: Decision Problems 
Decision Problem A

\section{Decision Problems}

2.1

Decision Problem A

Person 1 chooses between Option I and Option II - payoff in $\$$

\begin{tabular}{|c|c|c|c|c|c|c|}
\hline \multirow[b]{2}{*}{ No. } & \multicolumn{3}{|c|}{ Option I } & \multicolumn{3}{|c|}{ Option II } \\
\hline & Choice & Person 1 & Person 2 & Choice & Person 1 & Person 2 \\
\hline 1 & 6 & 100.00 & 100.00 & 0 & 40.00 & 40.00 \\
\hline 2 & $\odot$ & 88.80 & 111.20 & 0 & 40.00 & 40.00 \\
\hline 3 & $c$ & 88.40 & 111.60 & 0 & 40.00 & 40.00 \\
\hline 4 & $\odot$ & 87.80 & 112.20 & $C$ & 40.00 & 40.00 \\
\hline 5 & 6 & 87.20 & 112.80 & 0 & 40.00 & 40.00 \\
\hline 6 & $c$ & 86.40 & 113.60 & 0 & 40.00 & 40.00 \\
\hline 7 & 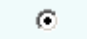 & 85.80 & 114.20 & 0 & 40.00 & 40.00 \\
\hline 8 & 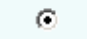 & 84.80 & 115.20 & 0 & 40.00 & 40.00 \\
\hline 9 & 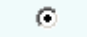 & 83.80 & 116.20 & 0 & 40.00 & 40.00 \\
\hline 10 & 6 & 82.80 & 117.20 & 0 & 40.00 & 40.00 \\
\hline 11 & $c$ & 81.40 & 118.60 & 0 & 40.00 & 40.00 \\
\hline 12 & 6 & 78.40 & 121.60 & 0 & 40.00 & 40.00 \\
\hline 13 & 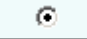 & 77.20 & 122.80 & 0 & 40.00 & 40.00 \\
\hline 14 & $c$ & 76.20 & 123.80 & 0 & 40.00 & 40.00 \\
\hline 15 & $c$ & 73.60 & 126.40 & 0 & 40.00 & 40.00 \\
\hline 16 & $c$ & 70.60 & 129.40 & $C$ & 40.00 & 40.00 \\
\hline 17 & $C$ & 66.60 & 133.40 & 6 & 40.00 & 40.00 \\
\hline 18 & 0 & 57.00 & 143.00 & 6 & 40.00 & 40.00 \\
\hline 19 & 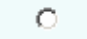 & 54.40 & 145.60 & 6 & 40.00 & 40.00 \\
\hline 20 & $C$ & 44.40 & 155.60 & 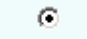 & 40.00 & 40.00 \\
\hline 21 & 0 & 28.60 & 171.40 & 6 & 40.00 & 40.00 \\
\hline 22 & 0 & 2.00 & 198.00 & 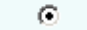 & 40.00 & 40.00 \\
\hline
\end{tabular}

Hint: Please decide as Person 1 by clicking either on Option I or Option II, i.e. you have to decide 22 times, which option you prefer. All payoffs are in US Dollars.

Please click "OK" to continue with Decision Problem B 
Decision Problem B

\section{Decision Problems}

2.1 Decision Problem B

Person 1 chooses between Option I and Option II

\begin{tabular}{|c|c|c|c|c|c|c|}
\hline \multirow[b]{2}{*}{ No. } & \multicolumn{3}{|c|}{ Option I } & \multicolumn{3}{|c|}{ Option II } \\
\hline & Choice & Person 1 & Person 2 & Choice & Person 1 & Person 2 \\
\hline 1 & $\odot$ & 200.00 & 0.00 & 0 & 0.00 & 0.00 \\
\hline 2 & $\epsilon$ & 200.00 & 0.00 & 0 & 10.00 & 10.00 \\
\hline 3 & $\odot$ & 200.00 & 0.00 & 0 & 20.00 & 20.00 \\
\hline 4 & $\odot$ & 200.00 & 0.00 & 0 & 30.00 & 30.00 \\
\hline 5 & 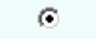 & 200.00 & 0.00 & $\mathrm{C}$ & 40.00 & 40.00 \\
\hline 6 & $\odot$ & 200.00 & 0.00 & 0 & 50.00 & 50.00 \\
\hline 7 & 6 & 200.00 & 0.00 & 0 & 60.00 & 60.00 \\
\hline 8 & $\odot$ & 200.00 & 0.00 & 0 & 70.00 & 70.00 \\
\hline 9 & $c$ & 200.00 & 0.00 & 0 & 80.00 & 80.00 \\
\hline 10 & $c$ & 200.00 & 0.00 & 0 & 90.00 & 90.00 \\
\hline 11 & $\odot$ & 200.00 & 0.00 & 0 & 100.00 & 100.00 \\
\hline 12 & 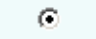 & 200.00 & 0.00 & 0 & 110.00 & 110.00 \\
\hline 13 & 6 & 200.00 & 0.00 & 0 & 120.00 & 120.00 \\
\hline 14 & 0 & 200.00 & 0.00 & $\odot$ & 130.00 & 130.00 \\
\hline 15 & 0 & 200.00 & 0.00 & $\odot$ & 140.00 & 140.00 \\
\hline 16 & 0 & 200.00 & 0.00 & $\odot$ & 150.00 & 150.00 \\
\hline 17 & $C$ & 200.00 & 0.00 & 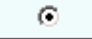 & 160.00 & 160.00 \\
\hline 18 & $C$ & 200.00 & 0.00 & $\odot$ & 170.00 & 170.00 \\
\hline 19 & 0 & 200.00 & 0.00 & $\odot$ & 180.00 & 180.00 \\
\hline 20 & $C$ & 200.00 & 0.00 & c & 190.00 & 190.00 \\
\hline 21 & $\mathrm{C}$ & 200.00 & 0.00 & 6 & 200.00 & 200.00 \\
\hline 22 & 0 & 200.00 & 0.00 & $\odot$ & 210.00 & 210.00 \\
\hline
\end{tabular}

Hint: Please decide as Person 1 by clicking either on Option I or Option II, i.e. you have to decide 22 times, which option you prefer. All payoffs are in US Dollars.

Please click "OK" to continue with some Additional Questions. 


\section{Additional Questions}

\section{Decision Problems}

\subsection{Additional Questions}

We have two final questions for you. So far, you made your decisions in the Decision Problems $\mathrm{A}$ and $\mathrm{B}$ based on your individual preferences. However, we are also interested in how certain representatives of your country would behave in the same decision situations. Therefore, suppose we are doing this experiment as a side event of a Conference of the Parties (COP) or a meeting of the subsidiary bodies (SBI or SBSTA). The representatives of each country responsible for the current climate policy negotiations are asked to participate in the experiment. The group of representatives of your country has to decide in Decision Problems $\mathrm{A}$ and $\mathrm{B}$ in the role of "Person 1". The group of representatives of another country takes on the role of "Person 2".

Please note that you can go back in order to remember your individual decisions in $\mathrm{A}$ and $\mathrm{B}$. Your answers to the following two questions do not affect the payment. The payment will be based only on the individual decisions you have made before.

Regarding Decision Problem A: In your opinion, how would the group of representatives of your country decide?

(c) the same way as I did.

$C$ compared to my decision, the decision of the group would lead to a distribution with more money for Person 1

$C$ compared to my decision, the decision of the group would lead to a distribution with less money for Person 1.

CI do not know.

Regarding Decision Problem B: In your opinion, how would the group of representatives of your country decide?

c. the same way as I did.

$C$ compared to my decision, the decision of the group would lead to a distribution with more money for Person 1

$C$ compared to my decision, the decision of the group would lead to a distribution with less money for Person 1 .

Cl do not know. 


\section{References}

Andreoni, J. and Miller, J. (2002): Giving According to GARP: An Experimental Test of the Consistency of Preferences for Altruism, Econometrica 70, 737-753.

Barrett, S. (1992): "Acceptable" Allocations of Tradable Carbon Emission Entitlements in a Global Warming Treaty, Combating Global Warming - Study on a Global System of Tradeable Carbon Emission Entitlements, 85113, New York, United Nations.

Barrett, S. (1994): Self enforcing International Environmental Agreements. Oxford Economic Papers 46, 878-894.

Blanco, M., Engelmann, D., and Normann, H.-T. (2006): A within Subject Analysis of OtherRegarding Preferences, Royal Holloway College, University of London, working paper, October 4, 2006.

Bolton, G.E. and Ockenfels, A. (2000): ERC. A Theory of Equity, Reciprocity and Competition, American Economic Review, 90, 166-193.

Bosello, F. and Roson, R. (2000): Carbon Emissions Trading and Equity in International Agreements, Milan: Fondazione Eni Enrico Mattei.

Brosig, J., Riechmann, T., and Weimann, J. (2007): Selfish in the End? An Investigation of Consistency and Stability of Individual Behavior, FEMM Working Paper No. 05, February 2007, Faculty of Economics and Management Magdeburg.

Buonanno, P., Carraro, C., Castelnuovo, E., and Galeotti, M. (2000): Efficiency and Equity of Emission Trading with Endogenous Environmental Technical Change, Draft.

Camerer, C.F. (2003): Behavioral Game Theory. Experiments in Strategic Interaction, Princeton, New Jersey, Princeton University Press.

Carraro, C. and Siniscalco, D. (1993): Strategies for the Protection of the Environment, Journal of Public Economics 52, 309-328.

Dannenberg, A., Riechmann, T., Sturm, B., and Vogt, C. (2007): Inequity Aversion and Individual Behavior in Public Good Games: An Experimental Investigation, ZEW Discussion Paper No. 07-034, Mannheim.

Engelmann, D. and Strobel, M. (2004): Inequity Aversion, Efficiency, and Maximin Preferences in Simple Distribution Experiments, American Economic Review 94, 857-869.

Fehr, E. and Gächter, S. (2000): Cooperation and Punishment in Public Goods Experiments, American Economic Review 90, 980-994.

Fehr, E. and Schmidt, K.M. (1999): A Theory of Fairness, Competition, and Cooperation, Quarterly Journal of Economics 114, 817-868.

Forsythe, R., Horowitz, J.L., Savin, N.E., and Sefton, M. (1994): Fairness in Simple Bargaining Experiments, Games and Economic Behavior 6, 347-369.

Güth, W., Kliemt, H., and Ockenfels, A. (2003): Fairness vs. Efficiency: An Experimental Study of (Mutual) Gift Giving, Journal of Economic Behavior and Organization 50, 456-475.

Güth, W., Schmittberger, R., and Schwarze, B. (1982): An Experimental Analysis of Ultimatum Bargaining, Journal of Economic Behavior and Organization 3, 367-388.

Kahneman, D., Knetsch, J.L., and Thaler, R.H. (1986): Fairness and the Assumptions of Economics, Journal of Business 59, 285-300.

Kemfert, C. and Tol, R.S.J. (2002): Equity, International Trade and Climate Policy, International Environmental Agreements: Politics, Law and Economics 2, 23-48. 
Lange, A. and Vogt, C. (2003): Cooperation in International Environmental Negotiations due to a Preference for Equity, Journal of Public Economics 87, 2049-2067.

Lange, A., Vogt, C., and Ziegler, A. (2007a): On the Importance of Equity in International Climate Policy: An Empirical Analysis, Energy Economics, forthcoming.

Lange, A., Löschel, A., Vogt, C., and Ziegler, A. (2007b): On the Self-serving Use of Equity Principles in International Climate Negotiations, ZEW Discussion Paper No. 07-025, Mannheim.

LeCocq, F., Hourcade, J.C., and le Pesant, T. (2000): Equity, Uncertainties and Robustness of Entitlement Rules, Journees Economie de l'Environnement du PIREE.

Ledyard, J.O. (1995): Public Goods. A Survey of Experimental Research, in: Kagel, J. H. and Roth, A. E. (Eds.), The Handbook of Experimental Economics, Princeton, NJ, Princeton University Press, 111-194.

Levati, M.V., Ploner, M, and Traub, S. (2007): Are Cooperators Efficiency- or Fair-minded? Evidence from a Public Goods Experiment, Jena Economic Research Papers, 2007-067.

Maddison, D.J. (1995): A Cost Benefit Analysis of Slowing Climate Change, Energy Policy 23, 337346

Manne, A.S., Mendelsohn, R.O., and Richels, R.G. (1995): MERGE - A Model for Evaluating Regional and Global Effects of GHG Reduction Policies, Energy Policy 23, 17-34.

Meyer, A. (2000): Contraction and Convergence: The Global Solution to Climate Change, London, Green Books.

Nordhaus, W.D. (1991): To Slow or Not to Slow: The Economics of the Greenhouse Effect, Economic Journal 101, 920-937.

Nordhaus, W.D. (1992): An Optimal Transition Path for Controlling Greenhouse Gases, Science 258, 1315-1319.

Nordhaus, W.D. and Yang, Z. (1996): RICE: A Regional Dynamic General Equilibrium Model of Optimal ClimateChange Policy, American Economic Review 86, 741-765.

Oosterbeek, H., Sloof, R., and van de Kuilen, G. (2004): Cultural Differences in Ultimatum Game Experiments: Evidence from a Meta-Analysis, Experimental Economics 7, 171-188.

Peck, S.C. and Teisberg, T.J. (1991): CETA: A Model for Carbon Emissions Trajectory Assessment, Energy Journal 13, 55-77.

Peck, S.C. and Teisberg, T.J. (1995): Optimal $\mathrm{CO}_{2}$ Control Policy with Stochastic Losses from Temperature Rise, Climatic Change 31, 19-34.

Ridgley, M.A. (1996): Fair Sharing of Greenhouse Gas Burdens, Energy Policy 24, 517-529.

Rose, A. (1992): Equity Consideration of Tradeable Carbon Emission Entitlements, in Anonymous, Combating Global Warming - Study on a Global System of Tradeable Carbon Emission Entitlements, 55-83, New York, United Nations.

Rose, A. and Stevens, B. (1993): The Efficiency and Equity of Marketable Permits for $\mathrm{CO}_{2}$ Emissions, Resource and Energy Economics 15, 117-146.

Rose, A., Stevens, B., Edmonds, J.A., and Wise M.A. (1998): International Equity and Differentiation in Global Warming Policy - An Application to Tradeable Emission Permits, Environmental and Resource Economics 12, 25-51.

Sturm, B. and Weimann, J. (2006): Experiments in Environmental Economics and some Close Relatives, Journal of Economic Surveys 20, 419-457.

Tol, R.S.J. (1997): On the Optimal Control of Carbon Dioxide Emissions - An Application of FUND, Environmental Modelling and Assessment 2, 151-163 
Tol, R.S.J. (1999): The Optimal Timing of Greenhouse Gas Emission Abatement, Individual Rationality and Intergenerational Equity, in: Carraro, C. (Ed.), International Environmental Agreements on Climate Change, 169-182, Dordrecht, Kluwer Academic Publishers.

Wooldridge, J.M. (2000): Introductory Econometrics. A Modern Approach, Cincinnati, Ohio et al., South-Western College Publishing. 